\title{
Evolution and Accuracy of Surface Humidity Reports*
}

\author{
Bruce Ingleby, David Moore, Chris Sloan, And Robert Dunn \\ Met Office, Exeter, United Kingdom
}

(Manuscript received 22 October 2012, in final form 2 May 2013)

\begin{abstract}
Until recently surface humidity was predominantly measured using psychrometers (wet- and dry-bulb thermometers). In some countries, often in conjunction with increased automation, the measurement technique has changed-usually to capacitive sensors. The scale of the change in instrumentation and the error characteristics of the operational instruments have not been well documented. This paper provides an overview of these operational instruments and their error characteristics, intended to be useful for climate and forecast users of the data. It also includes detailed results from comparisons of psychrometers and capacitive sensors with a chilled mirror reference instrument at a site in the United Kingdom under (near) operational conditions. The psychrometers performed well near saturation but underread at lower humidities; any large errors tended to be positive because of insufficient water supply to the wet bulb. New capacitive sensors perform well but they usually drift to higher values during deployment (except in arid climates); they perform best at lower humidities and need regular adjustment and recalibration. The natural variation of relative humidity and the differences between instruments are larger in daytime than at night. Changes in the U.K. synoptic network are described in order to put the intercomparisons into context. The instruments used in selected other countries are surveyed. There is a need for better documentation and real-time exchange of metadata on the instruments used and any changes. Capacitive sensors are also used on some radiosondes and aircraft; relevant studies are briefly reviewed and some parallels with surface usage are drawn.
\end{abstract}

\section{Introduction}

Surface humidity reports are used increasingly in climate studies, numerical weather prediction (NWP), and other applications. Especially for climate studies, systematic errors (biases) in humidity are important and should be minimized or at least documented. The Met Office has changed from using psychrometers to capacitive sensors at most of its stations, as they have become completely automated (see section 3). We encourage other countries to document details of their humidity instruments, observing practices, and error characteristics and any changes to them, as we found very little such documentation.

\footnotetext{
* Supplemental information related to this paper is available at the Journals Online website: http://dx.doi.org/10.1175/ JTECH-D12-00232.s1.

Corresponding author address: Bruce Ingleby, Met Office, FitzRoy Road, Exeter EX1 3PB, United Kingdom.

E-mail: bruce.ingleby@metoffice.gov.uk
}

Surface humidity has been examined by Dai (2006), Willett et al. (2007, 2013), and Simmons et al. (2010) in the context of climate change. Dai (2006) noted particular problems in very cold conditions (see also Lin and Hubbard 2004; Wong 2012). On the whole, these studies did not look at biases; however, Simmons et al. (2010) noted dry biases in low-level humidity from some types of radiosonde, especially around the 1990s. In the Met Office NWP system, surface humidity is assimilated in both regional and global models (Ingleby et al. 2013) and also used to update soil moisture (Dharssi et al. 2011). In NWP high relative humidity (RH) conditions are particularly important, as they are linked to poor visibility [in the regional U.K. forecasting system, visibility reports can have a significant effect on the humidity analysis; see Clark et al. (2008)]. Section 2 of this paper provides a basic description of the most common types of surface humidity measurements, instrument changes in various countries, and also a summary of radiosonde and aircraft humidity measurement. Section 3 describes the evolution of the U.K. synoptic network, the trials that have accompanied these changes, and the 
TABLE 1. Number of stations with at least 30 SYNOP reports during June 2011, the percentage of reports containing humidity, and the percentage of stations with at least 10 automated reports (as determined by the $i_{x}$ indicator of the SYNOP code; WMO 2011).

\begin{tabular}{lccc}
\hline \hline \multicolumn{1}{c}{ WMO region } & No. of stations & $\begin{array}{c}\text { Humidity } \\
\text { reports (\%) }\end{array}$ & $\begin{array}{c}\text { Automated } \\
\text { reports (\%) }\end{array}$ \\
\hline Africa & 662 & 97.7 & 22.4 \\
Asia & 1687 & 99.9 & 5.8 \\
South America & 447 & 98.3 & 2.2 \\
North and Central & 1169 & 94.8 & 68.8 \\
$\quad$ America & & & \\
Southwest Pacific & 1072 & 91.4 & 53.6 \\
Europe & 2519 & 96.2 & 54.9 \\
Antarctica & 83 & 27.2 & 72.3 \\
Globe & 7639 & 94.4 & 40.3 \\
\hline
\end{tabular}

error characteristics of the instruments tested. Results are presented for $\mathrm{RH}$, which is a secondary variable and a function of specific humidity $q$ and air temperature $T$. The findings are summarized in section 4 .

\section{Humidity measurement}

\section{a. Overview}

Humidity is usually measured $1.25-2 \mathrm{~m}$ above the ground in a screen. The WMO (2010, annex 1D) specifies a required measurement uncertainty of $1 \% \mathrm{RH}$ and estimates that the achievable uncertainty of solid state (including capacitive) sensors is $3 \% \mathrm{RH}$; chapter 1 in WMO (2010) also covers traceability to international standards as well as site layout. Humidity can be measured in various ways as described by WMO (2010, chapter 4), Sonntag (1994), and Wexler and Ruskin (1965). These describe the measurement principles and mention some error sources but do not make it clear how important these errors are in practice. Importantly, they do not document the drift in capacitive sensors. Psychrometers are the most widely used instruments at surface stations according to WMO (2010), but they cannot be used at fully automated stations. A survey of the humidity instruments used by European meteorological services in 2010 (M. Mair 2011, personal communication) suggests that unheated capacitive sensors are widely used, with limited use of heated capacitive sensors, chilled mirror sensors, and hair hygrometers. To the best of our knowledge, the great majority of operational measurements use natural ventilation. Unfortunately, the metadata collected by the World Meteorological Organization (WMO) do not include the humidity instrumentation used at surface land stations. Table 1 shows that some regions are much more automated-and hence more likely to use capacitive sensors-than others.
The global proportion of fully automated stations increased from 24.5\% in June 2006 to 31.1\% in June 2011. In both these months, $9.2 \%$ of stations were partially automated. The humidity reporting rate for Antarctica is rather low because humidity measurement is more difficult in very cold conditions. Reports are made in the alphanumeric surface synoptic observations (SYNOP) code or with the digital Binary Universal Format for Data Representation (BUFR) code (WMO 2011), usually as dewpoint temperature, but there is an option to report RH.

\section{b. Chilled mirror hygrometers}

These were used as reference instruments during the trials described later and some are used operationally in Switzerland (and for a time in the United States; see section $2 \mathrm{~g}$ ). A small mirror is cooled until dew forms on it; its temperature then gives the dewpoint. Some instruments cycle just above and just below the dewpoint. Chilled mirror instruments used on aircraft measure continuously (rapid changes of humidity can cause the measured value to overshoot). Thygan hygrometers (see section 3 ) have a cycle of approximately $10 \mathrm{~min}$, and the fan is only ventilating the mirror for the last part of the cycle-the measured dewpoint temperature is the average over about a minute while the fan is operating. Over time pollution or sea salt can deposit on the mirror and substantial deposits can cause erroneous readings. Thygan hygrometers have an automated cleaning mode whereby the mirror is cooled until condensation forms and then wiped with a leather pad. However, below $0^{\circ} \mathrm{C}$ a perfectly clean mirror will perform badly because of the lack of condensation sites (A. Vance 2012, personal communication). Determining the transition between dewpoint and frost point can be difficult.

\section{c. Psychrometers-Wet-bulb thermometers}

Psychrometers measure both dry- and wet-bulb temperatures from which the humidity is then calculated (e.g., WMO 2010, section 4.2), but Loescher et al. (2009, p. 1282) state that "it is very difficult to make wet-bulb psychrometric measurements in dry environments." There is a reservoir of distilled water and a cotton wick connects this to the wet bulb. The difference between the two temperatures is primarily a function of humidity and the airspeed over the wet bulb. However, the diameter of the wick, the length in contact with the wet bulb, and the shape and orientation of the wet bulb also affect results (Met Office 1981), so that each instrument design has its own psychrometer coefficient-see section 3. Wylie and Lalas (1992) provide much more discussion of the principles involved. In practice it can be difficult to install the wet-bulb wick correctly: some wicks are too 
tight. Grease or salt from fingerprints, sea salt, dust, or other contamination can reduce water supply to the wet bulb and result in the humidity recorded being too high (e.g., Visscher 1995). Extraneous heating of the wet bulb, via radiation or conduction (or excess length of wick between the reservoir and the wet bulb), would result in the derived humidity being too high. A particular problem for semiautomated systems is the reservoir drying out. At the other extreme, driving rain can sometimes wet the dry bulb; afterward, evaporation cools the dry bulb for a short time, affecting both temperature and derived RH (which will be too high).

In freezing conditions water will no longer spread up the wick and the wet (ice) bulb will dry out-this can take between $20 \mathrm{~min}$ and $48 \mathrm{~h}$ depending on the weather conditions. Careful intervention ("painting" water onto the bulb, inducing it to freeze and then waiting for the latent heat to dissipate) is needed to ensure that there is an ice bulb in place at the main observation times. Around $0^{\circ} \mathrm{C}$ latent heat release/uptake can affect the wet-bulb temperature, giving an erroneous humidity if the condition is not detected (see appendix of Harrison and Wood 2012; also Fig. 6e).

\section{d. Capacitive and other absorption/adsorption sensors}

Some materials change their properties as they absorb water vapor (or adsorb it to form a surface layer), and they are used in instruments from hair hygrometers to carbon hygristors, as well as polymer wafer capacitive sensors. Anderson (1995, p. 662) explained "why they respond to relative humidity $(\mathrm{RH})$ rather than to an absolute measure of humidity, such as vapor pressure or mixing ratio, over a wide temperature range." Remarkably, the sensors respond to $\mathrm{RH}$ with respect to water (as opposed to ice) even at very low temperatures. Anderson suggests that this is because a thin film of noncrystalline water is formed on the sensor material. Pang et al. (1996) found a small discontinuity in the sensor response at about $-2^{\circ} \mathrm{C}$ while keeping humidity constant at $97 \% \mathrm{RH}$, probably a result of a small portion of the water molecules forming ice crystals. Capacitive sensors are used in many automated weather stations (AWSs) and in many modern radiosondes. They need adjustment and calibration before use and minor temperature-related corrections to the $\mathrm{RH}$ are applied in real time (see, e.g., Anderson 1995)—sensors are supplied with a thermometer attached and software to perform this correction. Absorption/adsorption sensors react more slowly at low temperatures: this is a particular problem for upper-tropospheric radiosonde measurements. Many sensors also exhibit an increase in response time near saturation (Anderson 1995).
Differences in time lags between the humidity and temperature sensor can cause errors in the conversion of RH into specific humidity or dewpoint temperature.

Capacitive sensors can be subject to contamination from sea salt or chemicals, for example, sulfur compounds from agricultural sources (Visscher and Kornet 1994). At saturation pollutants may dissolve onto the sensor. Some Vaisala RS80 radiosondes had RH biases because of contamination from part of the packaging material (Wang et al. 2002). At surface stations the sensors are usually used with a filter to reduce contamination; however, the filter affects the time response of the instrument (van der Meulen 1988) and creates a microenvironment around the sensor. In operational experience at the Met Office, HygroClip sensors on buoys appear to suffer less contamination and drift than those on land. Environmental conditions (fewer pollutants) or the filter could be responsible. The sensors used on land have a fairly close-fitting nonhygroscopic polytetrafluoroethylene (PTFE) membrane, whereas the buoy sensors have hygroscopic sintered metal filters and are placed in a small box with PTFE "windows."

Dery and Stieglitz (2002) and Makkonen and Laakso (2005) found spurious high humidities in the Arctic resulting from icing. Makkonen and Laakso (2005) found that accurate measurement was possible using a heated sensor (both the ambient temperature and the temperature of the sensor are measured). They also found good agreement between heated and unheated sensors below about $60 \% \mathrm{RH}$. At very low temperatures, which were mainly caused by radiative cooling, the humidity tended to be close to ice saturation (see their Fig. 7); we speculate that this may be the case at other polar stations as well.

\section{e. WMO intercomparisons}

There have been two WMO intercomparisons of surface humidity measurements. Skaar et al. (1989), summarized in Skaar and Hegg (1989), tested various instruments suitable for AWSs over two years in Norway. As reference they used a chilled mirror hygrometer, supplemented above $0^{\circ} \mathrm{C}$ by reference psychrometers; the psychrometers were heated or aspirated (ventilated by fan). Below $0^{\circ} \mathrm{C}$ they noted particular problems with all measurement techniques. Also below $0^{\circ} \mathrm{C}$ they found that humidity was about $2 \%-3 \% \mathrm{RH}$ higher inside the screen than outside it. The effectiveness of this work in informing the transition to electronic humidity sensors was reduced because the report lacked clarity and no version appeared in the peer-reviewed literature.

Lacombe et al. (2011) tested various capacitive sensors in Algeria. The reference was a Thygan chilled mirror hygrometer (manufactured by Meteolabor). 
TABLE 2. Summary of humidity sensors in the 2008 Camborne trial. For the SAMOS psychrometer $T_{w}$ was measured but only $T_{d}$ was stored.

\begin{tabular}{llll}
\hline \hline \multicolumn{1}{c}{ Instrument } & \multicolumn{1}{c}{ Type } & Output & \\
\hline Thygan1 & Chilled mirror & $T_{d}$ & Aspirated; reference measure \\
Thygan2 & Chilled mirror & $T_{d}$ & Aspirated; reference measure \\
Psychrometer & Wet/dry bulb & $T_{w}$ & Dry-bulb PRT used for Thygan RH \\
HygroClip1 from 3 Mar & Capacitive & RH & Previously located at Aberporth, United Kingdom, for 8 months \\
HygroClip2 from 3 Mar & Capacitive & RH & Previously located at St Mawgan, United Kingdom, for 5 months \\
HygroClip3 & Capacitive & RH & Connector failed, statistics not shown \\
HygroClip4 & Capacitive & RH & New sensor \\
HygroClip5 & Capacitive & RH & New sensor \\
HygroClip6 & Capacitive & RH & Previously located at Lossiemouth, United Kingdom, for 8 months \\
SAMOS psychrometer & Wet/dry bulb & $T_{d}$ & Operational at the time \\
SAMOS HygroClip & Capacitive & RH & SAMOS backup, replaced 30 Jul \\
\hline
\end{tabular}

The capacitive sensors performed well. Some of the aspirated systems performed relatively poorly, possibly because of reversed airflow through the system at higher wind speeds, allowing heating from the fan motor to affect the measurements.

\section{f. Capacitive sensor drift}

Visscher and Kornet (1994) found that all but one of the capacitive sensors they investigated drifted higher, mostly by $1 \%-2 \% \mathrm{RH} \mathrm{yr}^{-1}$. Our experience (see section 3 ) is broadly similar. Richardson et al. (2000) found that one capacitive sensor was $4 \% \mathrm{RH}$ too high before their intensive observation period and $6 \% \mathrm{RH}$ too high afterward. The Vaisala and Rotronic capacitive sensors tested by Skaar et al. (1989) drifted up by between $0.3 \%$ and $1.9 \%$ RH over a year. ${ }^{1}$ Burt (2012) suggests that

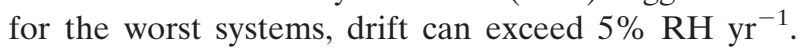
Lacombe et al. (2011) found little or no drift, probably related to the drier conditions in their trial. The drift to higher values is likely to be related to episodes when the sensor is saturated (excess water condensing on the sensor).

\section{g. Known changes in other countries}

This section summarizes information from published sources and from informal enquiries made to a few other national meteorological services. The U.S. National Weather Service (NWS) originally used psychrometers, but lithium chloride hygrothermometers (also known as dew cells) were introduced in the early 1960s and in the mid-1980s these were replaced by chilled mirror instruments (Gaffen and Ross 1999, and references). Gaffen and Ross did not find any clear changes in humidity biases resulting from the changes in instrumentation.

\footnotetext{
${ }^{1}$ The drift values given by Skaar et al. (1989) are negative but are for reference RH minus test $\mathrm{RH}$; we use the opposite convention: test $\mathrm{RH}$ minus reference $\mathrm{RH}$.
}

However, the chilled mirror hygrothermometers (from Technical Services Laboratory) required more frequent maintenance than the other elements of the Automated Surface Observing System (ASOS), and between late 2002 and 2006 they were replaced with capacitive sensors (NWS 2002, and http://www.nws.noaa.gov/asos/). The ASOS sensors are aspirated unlike most AWSs.

Canada used dew cells for some of their automatic measurements, but also Vaisala HMP45/46 sensors. The dew cells have been phased out since 2008 and most/all of the measurements now come from Vaisala HMP series sensors (R. Nitu 2012, personal communication). Vincent et al. (2007) found changes in biases at Canadian stations when dew cells were introduced. The Netherlands changed to use capacitive sensors in the 1980s and has since used sensors from Rotronic, Vaisala, and E+E Elektronik (H. Bloemink 2012, personal communication). South Korea introduced resistance humidity sensors in 2000 but these were soon replaced by capacitive sensors (J. Won 2011, personal communication). In general, former British colonies followed U.K. practice (and often had U.K.-supplied psychrometers), but screens tended to be thicker/larger (S. Palmer 2011, personal communication); some of these countries are now moving to capacitive sensors.

WMO Commission for Instruments and Methods of Observation (CIMO) Technical Conferences (see http:// www.wmo.int/pages/prog/www/CIMO/cimo-tecometeorex.html) provide snapshots of the situation in other countries. A set of Global Climate Observing System (GCOS) climate monitoring principles has been widely agreed upon [see http://www.wmo.int/pages/prog/ gcos/index.php?name $=$ ClimateMonitoringPrinciples; also Trenberth et al. (2002)]. These principles stress the need for the impact of system changes to be assessed and for metadata to be available. There is little or no evidence of such assessment of many of the changes mentioned above and the lack of global metadata on humidity instruments has already been noted. 
TABLE 3. Psychrometer coefficient $A\left(\mathrm{~K}^{-1}\right)$, taken from Table VII of Met Office (1981) and originally from Jelinek et al. (1903). The values given for natural ventilation have been used for all operational measurements.

\begin{tabular}{lll}
\hline \hline \multicolumn{1}{c}{ Ventilation } & $T_{w} \geq 0^{\circ} \mathrm{C}$ & $T_{w}<0^{\circ} \mathrm{C}$ \\
\hline Natural $\left(1-1.5 \mathrm{~m} \mathrm{~s}^{-1}\right)$ & 0.000799 & 0.000720 \\
Forced $\left(>3.5 \mathrm{~m} \mathrm{~s}^{-1}\right)$ & 0.000666 & 0.000594 \\
\hline
\end{tabular}

Lucas (2010) created a high-quality surface dewpoint database for Australia, using data from 58 stations from 1957 to 2003 . He found a peak in the number of homogeneity break points per year in the mid-1990s, corresponding to AWS data becoming the official measurements. Relative to a reference series (mainly from mercury-in-glass psychrometers) platinum resistance thermometer (PRT) psychrometers had an overall dewpoint bias of $-0.5^{\circ}$ and stations with capacitive sensors had a bias of about $-0.3^{\circ}$ but a relatively high variability. Operationally, Australian stations use a psychrometer coefficient $A=0.0007886 \mathrm{~K}^{-1}$; however, lowering this to $0.0007 \mathrm{~K}^{-1}$ for PRT psychrometers gave a better fit to the reference data (see section $3 \mathrm{~d}$ for further discussion of the psychrometer coefficient).

\section{h. Radiosonde, aircraft, and marine humidity measurements}

Errors in radiosonde humidity have been extensively studied (e.g., Miloshevich et al. 2009; Dai et al. 2011). Wang et al. (2002) found that radiosonde temperatures were too warm and humidities too dry in the lowest levels, at least during daytime, probably a result of prelaunch radiative heating of the sensors. This discourages use of near-surface radiosonde $\mathrm{RH}$ as a reference for surface screen $\mathrm{RH}$. When a radiosonde emerges from cloud into clear air, some humidity sensors read too high for a short period-analogous to problems with screen humidities following saturation. The Vaisala RS92 radiosonde has two humidity sensors; they are alternately heated and used for measurement to minimize such problems.

Automated aircraft reports are made by Aircraft Meteorological Data Relay (AMDAR) and Tropospheric Airborne Meteorological Data Reporting (TAMDAR) systems from long- and short-haul flights, respectively. Originally, both systems reported temperature and wind but not humidity. A small but growing proportion of aircraft now report humidity, especially over North America, but the geographical spread is increasing. Moninger et al. (2010) and Gao et al. (2012) found positive impact on NWP from TAMDAR humidity reports. These use capacitive sensors with a very fast response and a hydrophobic coating (N. Jacobs 2012, personal communication). The Water Vapor Sensing System, version 2 (WVSS-II), uses a diode laser system to measure the mixing ratio as part of some AMDAR systems, and the data are useful for airline operations and regional NWP (e.g., Baker et al. 2011). Preliminary results from monitoring in the Met Office global NWP system suggest that the fit of aircraft humidity to shortrange forecasts is broadly similar to that of radiosonde humidity, with the fit being slightly better for AMDAR than TAMDAR data.

Ingleby (2010) discusses the availability of marine humidity reports and their performance relative to shortrange forecasts: the comparison is worse in daylight than at night and buoy reports appear somewhat better than ship reports.

\section{Instrument changes and trials at the Met Office}

\section{a. History}

To provide a longer-term context for recent changes, a brief history is provided. For most of the twentieth century, most Met Office stations used psychrometers in naturally ventilated Stevenson screens (with a change from measurement in Fahrenheit to Celsius on 1 January 1961). In the late 1980s, the Met Office deployed moored buoys and a few remote AWSs with capacitive humidity sensors. At other stations, replacement of mercury-inglass with PRTs ${ }^{2}$ started around 1990 but took several years. The use of PRTs enabled partial automation-the Semiautomatic Meteorological Observing System (SAMOS) - and hence an expansion of the network (Green 2010). At SAMOS stations the reservoir was refilled and the wet-bulb wick replaced weekly; this formed the primary humidity measurement. In freezing conditions the humidity measurement came from capacitive sensors at unmanned SAMOS stations. There have also been minor changes to the thermometer diameter and to the wicks used (originally wicks were boiled at the station before use to make sure they were free of grease, but now the wicks are supplied "preboiled"). The Met Office $(1982,2009)$ provides guidance to the Met Office and collaborating observers on the maintenance and use of surface instruments.

Wooden Stevenson screens were replaced with plastic ones from 2002 onward. Perry et al. (2007) found this gave mean differences up to about $\pm 1 \% \mathrm{RH}$ : the differences were slightly larger at low wind speeds and

\footnotetext{
${ }^{2}$ As discussed in Met Office (1981), stem heat conduction of a PRT will differ from that of a mercury-in-glass thermometerthe length of thermometer stem covered by the wick can be modified in order to retain use of the same psychrometer coefficient.
} 
a) Relative Humidity, 13 February 2008

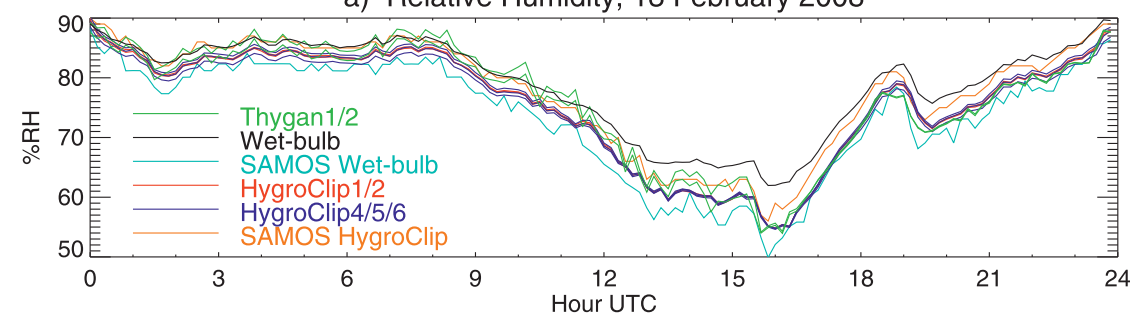

b) Thygan RH difference, 13 February 2008

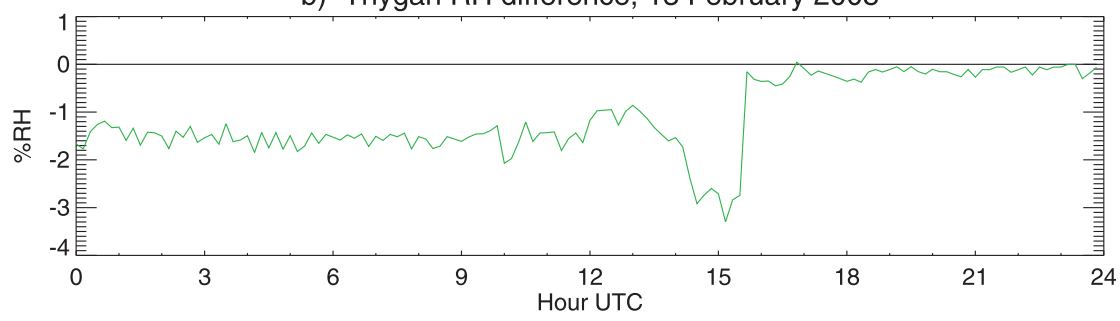

c) Relative Humidity, 23 March 2008

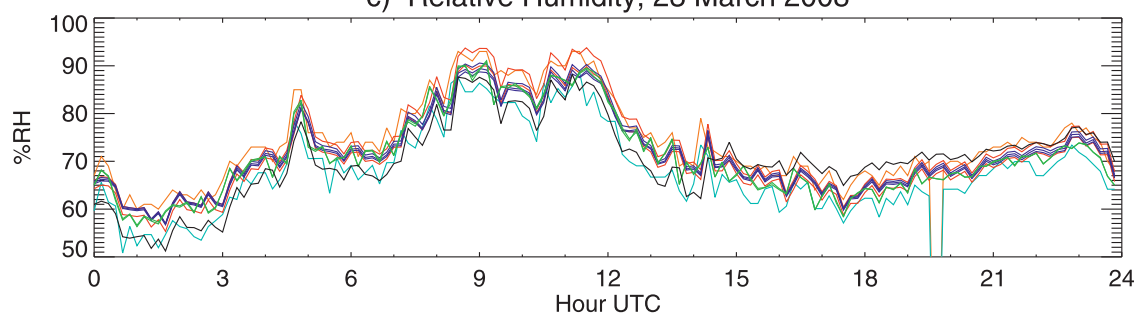

d) Relative Humidity difference, 23 March 2008

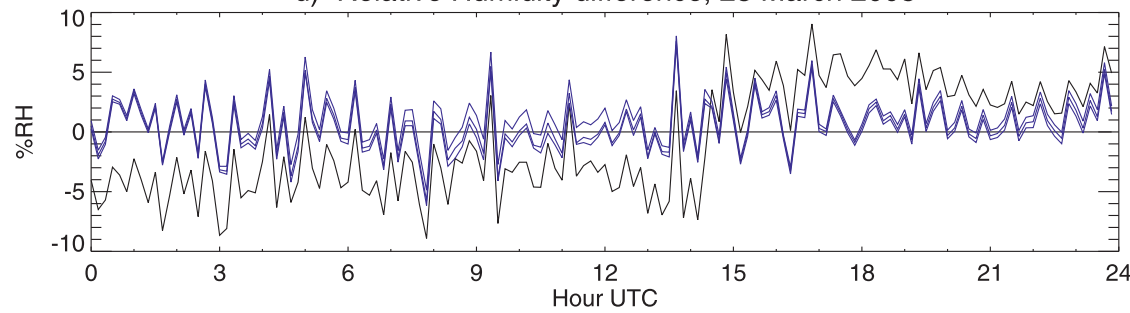

e) Relative Humidity, 1 April 2008

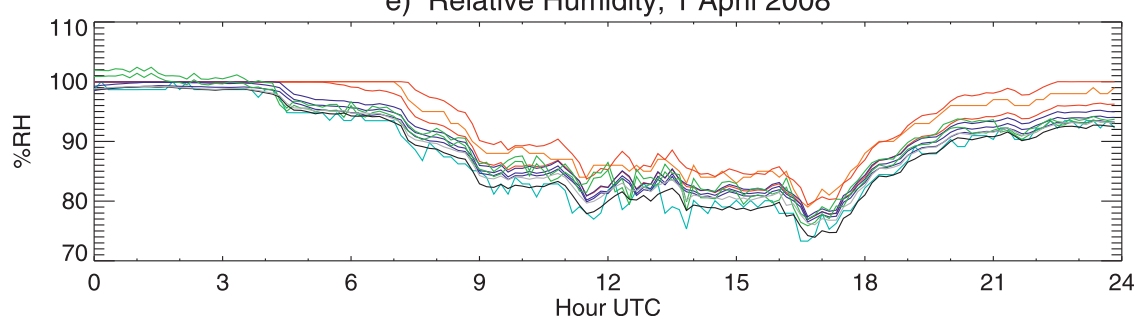

FIG. 1. (a),(c),(e) RH on selected days in the 2008 Camborne trial. See key in (a) for color coding. (b) Difference between the two Thygan chilled mirror hygrometers (Thygan2 Thygan1). (d) Differences from the mean of Thygan1 and Thygan2 for selected instruments.

smaller at high wind speeds. A trial in 2002-03 compared capacitive sensors (from Vaisala and Rotronic) with a chilled mirror reference and indicated that they met the Met Office requirements, and in some conditions gave better measurements than a psychrometer (W. Sparks and D. B. Hatton 2003, unpublished manuscript).
Trials performed in 2008 and 2011-12 are described below and provide a unique insight into how operational instruments perform in practice. The different trials found somewhat different biases in the sensors at high RH.

In 2008-09 as part of the Meteorological Monitoring System (MMS) project, Rotronic HygroClip MP100H 
capacitive humidity sensors were installed at all Met Office stations (previously four different capacitive instruments were in use) and replaced psychrometers as the primary humidity measuring instrument at unmanned stations. SAMOS and MMS temperatures and humidities are 1-min averages (made up of four 15-s samples). By June 2011 the Met Office had 120 automated stations reporting and 37 stations with some manual input (the latter still use psychrometers as the primary instrument at present). The Met Office has acquired 10 Thygan hygrometers and during 2013 some of these will be deployed to operational stations. While trials are essential for assessing changes, operational usage can uncover further instrument "features" because of a wider range of environmental conditions and instrument variation between manufactured batches.

Overall, psychrometers remained the main humidity instrument during the initial, partial automation, but since 2008-09 capacitive sensors have been the primary instrument at all unmanned stations. Results from several stations suggest that the move to capacitive sensors has slightly increased reported RH values (see below for results from Camborne). This has probably had a larger effect than the other changes mentioned above, although the Australian move to PRTs (see section $2 \mathrm{~g}$ ) had noticeable effects.

\section{b. Adjustment and calibration}

Capacitive sensors are adjusted and calibrated at the Met Office headquarters and then (ideally within a few weeks) deployed at a station for a year. They may be returned early if a problem is suspected. The worst of the returned sensors are discarded; the rest are cleaned, readjusted, recalibrated, and redeployed. The HygroClip $\mathrm{MP} 100 \mathrm{H}$ is adjusted using readings at $35 \%$ and $80 \% \mathrm{RH}$ (reference points were specified by Rotronic). The newer HygroClip2 can use up to five user-selected readings. The adjustment is chosen so that the sensors read about $0.5 \%$ $\mathrm{RH}$ lower than the reference-in expectation that they will drift to higher values over time. After adjustment six sensors are checked against a laboratory chilled mirror hygrometer inside an environmental chamber at a temperature of $10^{\circ} \mathrm{C}$; sensors that agree within $\pm 2 \% \mathrm{RH}$ are accepted, while others are readjusted and rechecked. The laboratory hygrometer is periodically calibrated at the National Physical Laboratory to provide traceability to national and international standards. The sensors show some hysteresis with higher values following near saturation: this effect is just under $1 \% \mathrm{RH}$ for new sensors but larger for older sensors. ${ }^{3}$ The highest test humidity is

\footnotetext{
${ }^{3}$ Pang et al. (1996) looked at the hysteresis of capacitive sensors and suggested a way of almost eliminating it.
}

98\%-99\% RH-not higher in order to prevent condensation in the pipe work and reference instrument. The uncertainty of the sensors is estimated at about $2 \% \mathrm{RH}$ over the range $10 \%-95 \% \mathrm{RH}$ and about $3 \% \mathrm{RH}$ for $95 \%-100 \%$ RH. The adjustment and calibration represents a substantial fraction of the total cost of operating the capacitive sensors (details from N. Mander 2011, 2013, personal communication).

\section{c. 2008 Camborne trial: Description}

In 2008 a trial was performed at the meteorological station (WMO identification number $03808 ; 50.218^{\circ} \mathrm{N}$, $5.327^{\circ} \mathrm{W}, 87 \mathrm{~m}$ above sea level) just west of Camborne in Cornwall, United Kingdom. The site is about $2.5 \mathrm{~km}$ from the coast; the climate is relatively wet and windy and without extreme temperatures. The station is manned-because it is also a radiosonde station with responsibility for two other autosonde sites. We present trial results from 26 January to 3 September for the instruments listed in Table 2. The trial psychrometer and six HygroClips were located in a Stevenson screen (to match operational practice), with two Thygan chilled mirror sensors about $5 \mathrm{~m}$ to the south (see supplemental material for details of the sensor mounting and photographs of the site). Data from the operational SAMOS instruments (about $5 \mathrm{~m}$ west of the trial screen) were also used. Three of the HygroClips had previously been returned from other stations with suspect performance: in the trial, sensors 1 and 2 had relatively large errors, whereas sensor 6 performed quite well. Three of the sensors were new: sensors 4 and 5 performed well but sensor 3 fluctuated wildly at times and was discarded.

The Thygans usually produce measurements every $10 \mathrm{~min}$ (occasionally at either 9 or $11 \mathrm{~min}$ ) —all instruments were sampled every $10 \mathrm{~min}$, but this did not necessarily correspond to Thygan updates. The Thygan temperatures were up to $2^{\circ} \mathrm{C}$ higher than the screen temperatures at noon on some sunny days; Lacombe et al. (2011) noted a similar problem. So, the PRT air temperature $T$ was used to convert the Thygan dewpoints $T_{d}$ to $\mathrm{RH}$ :

$$
\mathrm{RH}=\frac{e_{s}\left(T_{d}\right)}{e_{s}(T)} 100 \% .
$$

The "enhancement factor" 4 was approximated as 1 following operational practice. The saturation vapor pressure $e_{s}(\mathrm{hPa})$ was calculated from temperature $T\left({ }^{\circ} \mathrm{C}\right)$ as

\footnotetext{
${ }^{4}$ The enhancement factor is the ratio of the saturated vapor pressure of water in moist air to the saturated vapor pressure of pure water. It is 1 for ideal gas systems but is slightly greater than 1 in practice (e.g., Sonntag 1994).
} 
a) Mean Reference $\mathrm{RH}$ and windspeed $\times 10$

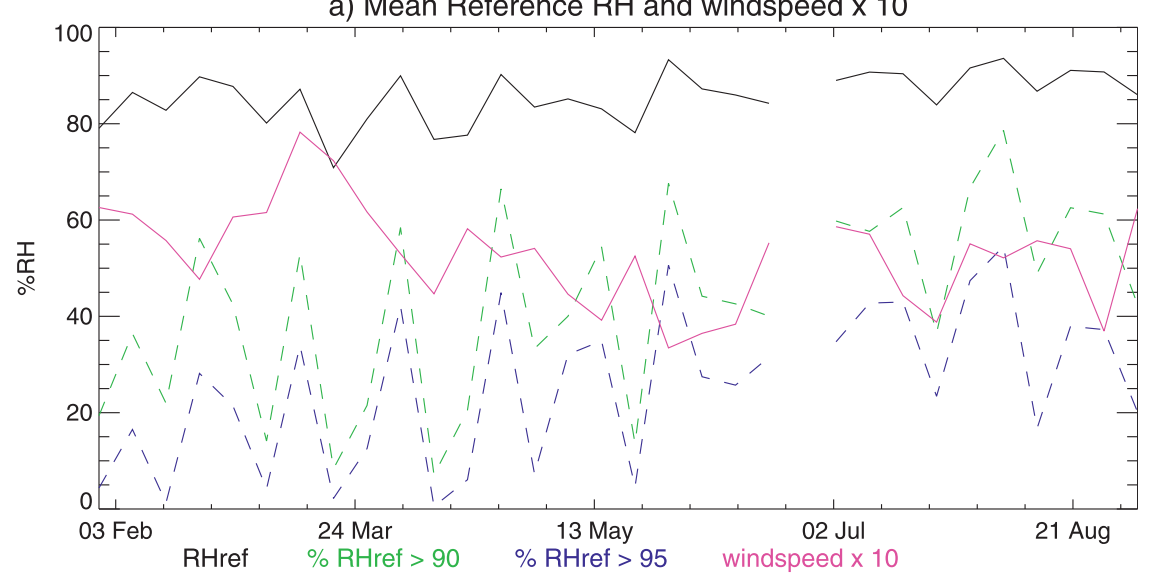

b) Relative Humidity mean difference

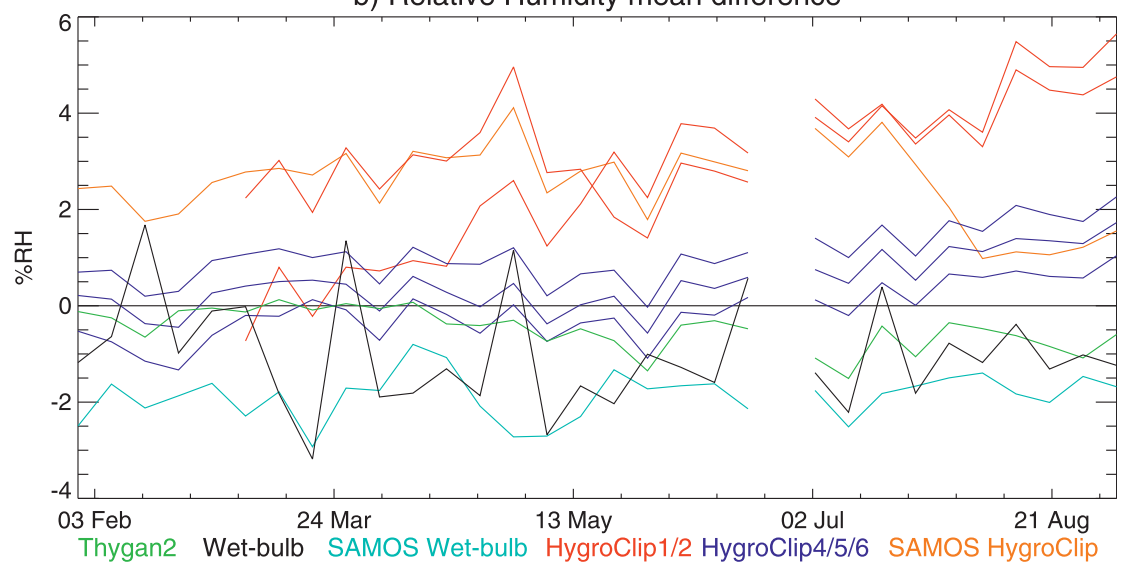

c) Relative Humidity SD of difference

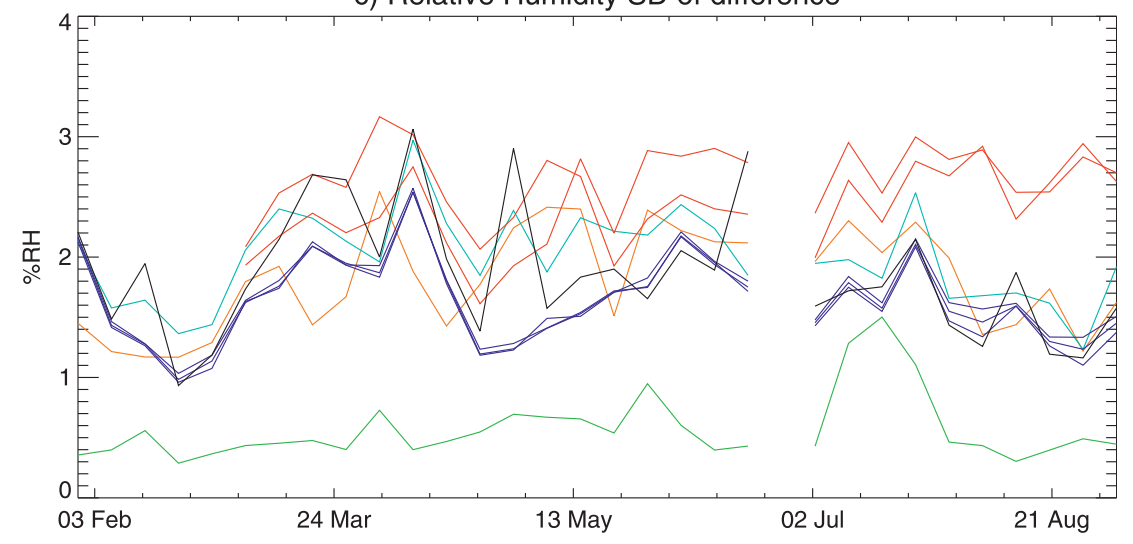

FIG. 2. (a) Mean reference RH (black) and percentage of the time over $90 \%$ and $95 \%$ RH (green and blue dashed lines, respectively) by week, omitting 22-29 Jun because of poor sampling. Mean wind speed at $10 \mathrm{~m}$ is also shown (purple line, $10^{1} \mathrm{~m} \mathrm{~s}^{-1}$ ). (b),(c) Mean and SD of differences from the reference $\mathrm{RH}$ using data points every $10 \mathrm{~min}$; colors as in key. Because the reference $\mathrm{RH}$ is the average of the two Thygans, the green lines are Thygan2 - Thygan1 in (b) and the SD of this difference in (c).

$$
e_{s}(T)=6.1070 \exp \left(\frac{17.38 T}{239+T}\right)
$$

because this variant of the Magnus-Tetens formula was used in SAMOS. Alternative formulas [such as Eq. (7) of Sonntag (1994)] yield very similar results. The psychrometer equation [Eq. (3)] was used to convert psychrometer wet-bulb temperature $T_{w}$ to vapor pressure:

$$
e=e_{s}\left(T_{d}\right)=e_{s}\left(T_{w}\right)-A p\left(T-T_{w}\right) .
$$


a) Mean Reference $\mathrm{RH}$ and windspeed x 10

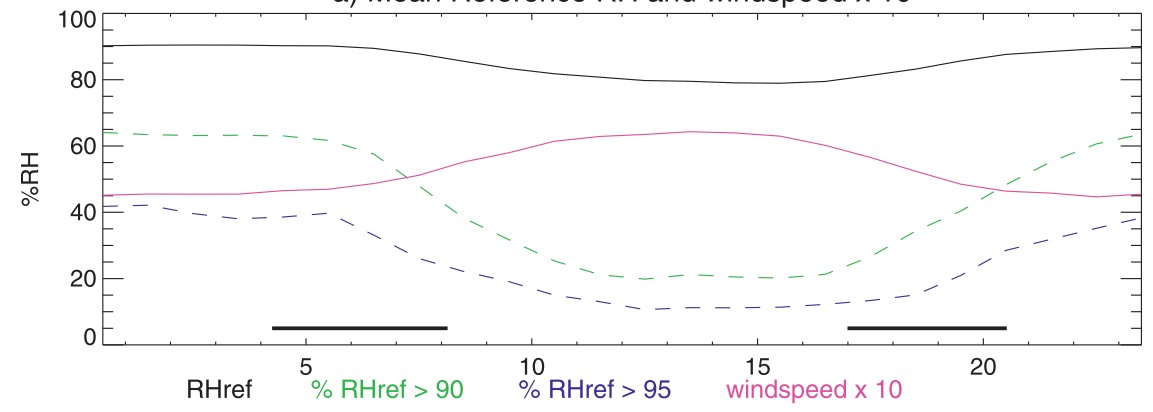

b) Relative Humidity mean difference

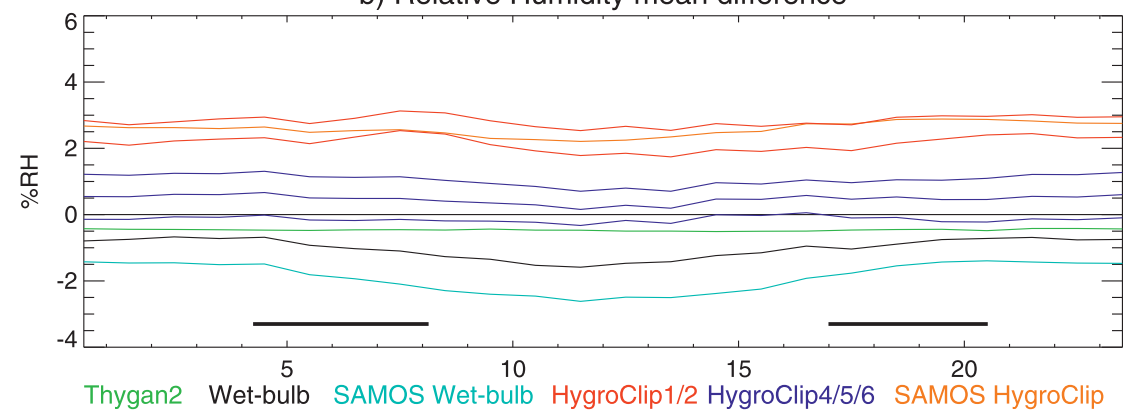

c) Relative Humidity SD of difference

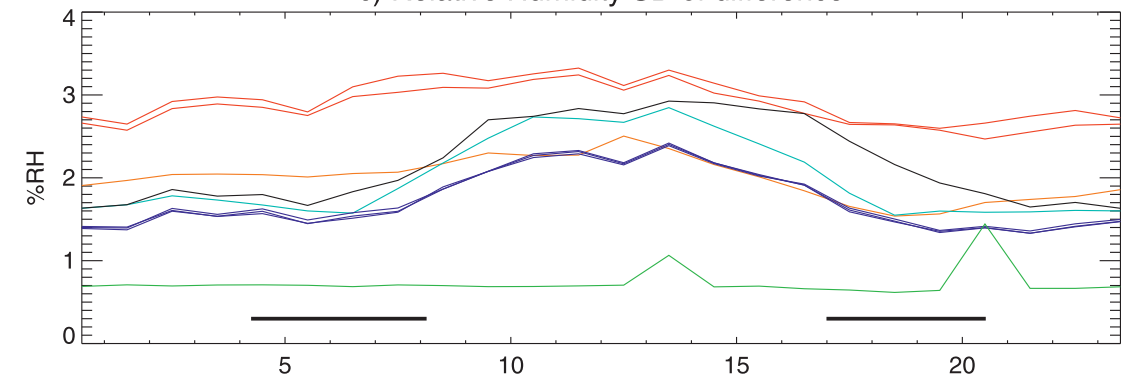

d) Relative Humidity SD within each hour

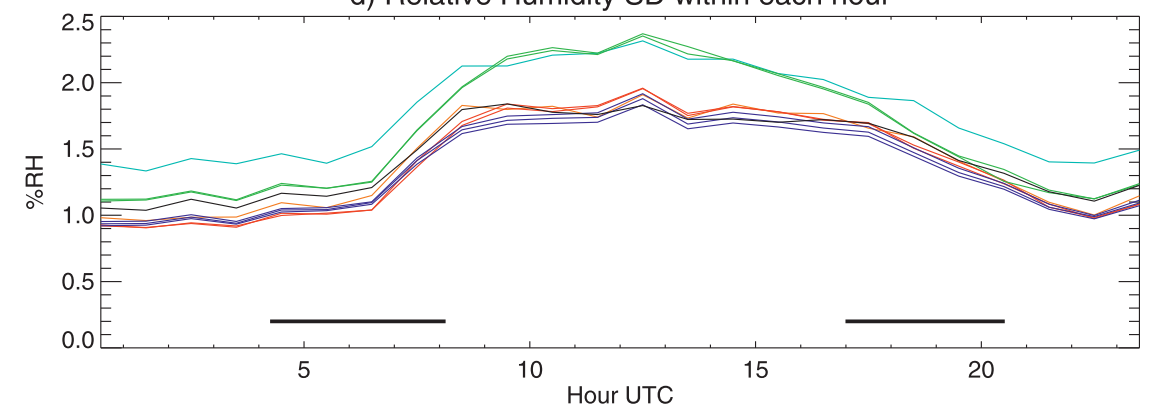

FIG. 3. (a)-(c) As in Fig. 2, but for the diurnal cycle (first point is average over all days from 0000 to 0050 UTC, etc.). (d) Mean of SD calculated for each 60-min period, calculated separately for the two Thygans, but the two green lines are very similar. Black lines above the $x$ axis give the range of sunrise and sunset times during the trial.

In Met Office practice, the pressure $p$ is taken as $1000 \mathrm{hPa}$ for stations up to about $1000 \mathrm{~m}$ above sea level (for an actual $p$ of $900 \mathrm{hPa}$ and $50 \% \mathrm{RH}$, this gives an error of about $2 \% \mathrm{RH}$; errors are less for higher $\mathrm{RH}$ and most U.K. stations are at altitudes below $300 \mathrm{~m}$ ). Table 3 shows the values of the psychrometer coefficient $A$ used. Loescher et al. (2009) found that $A$, rather than constant, becomes smaller at high RH. However, the humidity is 


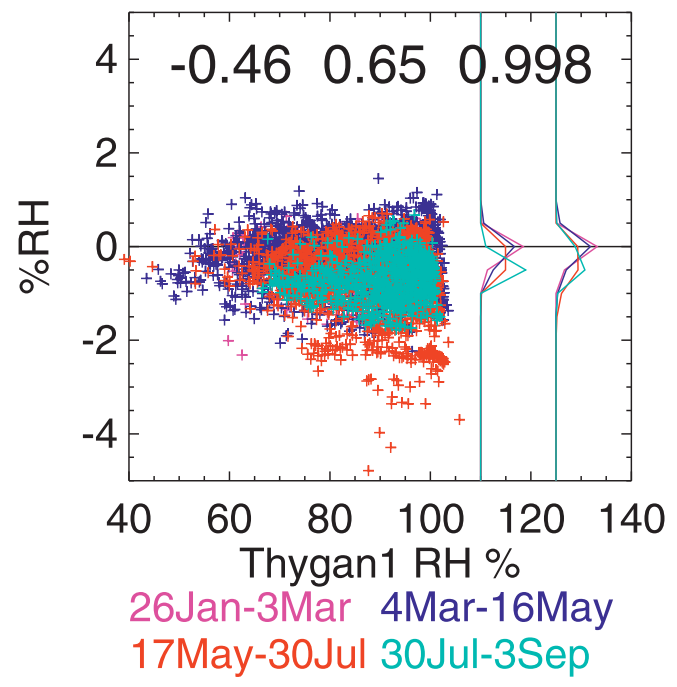

FIG. 4. Scatterplot of Thygan2 - Thygan1 RH vs Thygan1 RH, hourly data, color coded by date-see key. Bolded numbers are the mean and SD of the difference and the correlation between Thygan 2 and Thygan 1 hourly mean $\mathrm{RH}$ over the whole period, respectively. Two sets of lines at the right-hand side are the frequency distributions of the difference calculated for Thygan $1 \mathrm{RH}$ of $70 \% \pm$ $2.5 \% \mathrm{RH}$ and $95 \% \pm 2.5 \% \mathrm{RH}$ (offsets of 110 and 125 used for figure).

less sensitive to $A$ at high RH (small $T-T_{w}$ ). Harrison and Wood (2012) show the dependence of $A$ on the rate of ventilation. Their Eq. (5) is

$$
\begin{aligned}
A_{\text {eff }}(u) & =A_{\infty}+A_{c} \exp \left(-u / u_{\min }\right) \\
& =0.00074+0.00034 \exp (-u / 1.3)
\end{aligned}
$$

using the fitted values from their Fig. 5; $u$ is the wind speed at screen level, taken as $70 \%$ of the $10-\mathrm{m}$ wind speed (see the caption to their Fig. 7).

In the results below, HygroClip RH and psychrometer RH derived from Eqs. (2) and (3) are compared with Thygan RH calculated from Eqs. (1) and (2). Data were omitted during occasional 20-min Thygan reboots and on 11 occasions when the psychrometer RH exceeded $101 \%$ RH apparently because of wick changing. Data were also omitted for $12 \mathrm{~h}$ each on 3 March and 16 May when some of the HygroClips were replaced. There are gaps in the records for one or more instruments, including 17-18 February (Thygan2), 25-28 May (Thygan1 and 2), and 22-27 June (Thygan2 and HygroClips).

\section{d. 2008 Camborne trial: Results}

Figure 1 shows time series of RH and RH differences for selected days, and Fig. 2 shows weekly averages over the whole trial period. The Thygan humidities had occasional differences of up to $1.5 \% \mathrm{RH}$, with Thygan 1 usually reading higher than Thygan2: Fig. $1 \mathrm{~b}$ shows a sudden reduction of the difference by the weekly automatic cleaning of a mirror around 1600 UTC on 13 February. Figures $2 b$ and $2 c$ show the weekly bias between them and the standard deviation (SD) of the difference, which was generally about $0.5 \% \mathrm{RH}$. The mean of the two Thygan humidities is used as the reference for the other instruments.

The trial psychrometer is about $1 \% \mathrm{RH}$ drier than the reference on average but with notable week-to-week variability (Fig. 2b, black line). Figure 1d shows the largest jump, of about $8 \% \mathrm{RH}$, which corresponded with the weekly changing of the wick just before 1500 UTC on 23 March. The SAMOS psychrometer is about 2\% RH drier than the reference but shows less week-to-week variability (Fig. 2b, light blue line).

The "good" HygroClips (blue lines) have differences from the reference of typically $1.5 \% \mathrm{RH}$ and gradually more positive biases (Figs. 2b,c). The "poor" HygroClips (red lines) and the SAMOS HygroClip (orange) have somewhat larger SDs and much larger biases. The SAMOS HygroClip was replaced on 29 July 2008 (the replacement sensor was calibrated nine months earliera longer gap than desirable). Figure 1e suggests a tendency for the HygroClips to bunch together at lower RH but to spread out in nearly saturated conditions. Two of the sensors continued to show $100 \% \mathrm{RH}$ for about four hours after the others indicated subsaturated conditions. [Figure 2 of van der Meulen (1988) shows that the filters used can affect the response of sensors after fog.] The capacitance-RH relationship used can give values over $100 \% \mathrm{RH}$, but a maximum of $100 \% \mathrm{RH}$ is applied by the sensor software. Without this limit the errors at high RH would be worse.

Figure 3 shows the diurnal cycle in a similar format to Fig. 2. As expected, mean RH is higher overnight. During daytime the dryness of the psychrometers is greater because the bias is worse at lower RH (see scatterplots below). The SD of the differences from the reference for the psychrometers and the better-performing HygroClips is markedly higher during daytime than it is at night. This seems to be linked to genuinely higher natural variability during the day shown by all the instruments (Fig. 3d; the extra variability shown by the Thygans seems to come from the mismatch, by up to nine minutes, between the dewpoint temperature and the air temperature used to convert it to $\mathrm{RH})$. At night RH is typically quite high-so will not change much if there is rain. During daytime broken cloud will also affect $\mathrm{RH}$ via the temperature (specific humidity diurnal variation is shown in Fig. S5 in the supplemental material); however, the larger turbulent fluxes during daylight hours are probably more important.

Figure 4 shows a scatterplot of the Thygan 2 against Thygan1 RH-the two agree very well. Figure 5 shows 

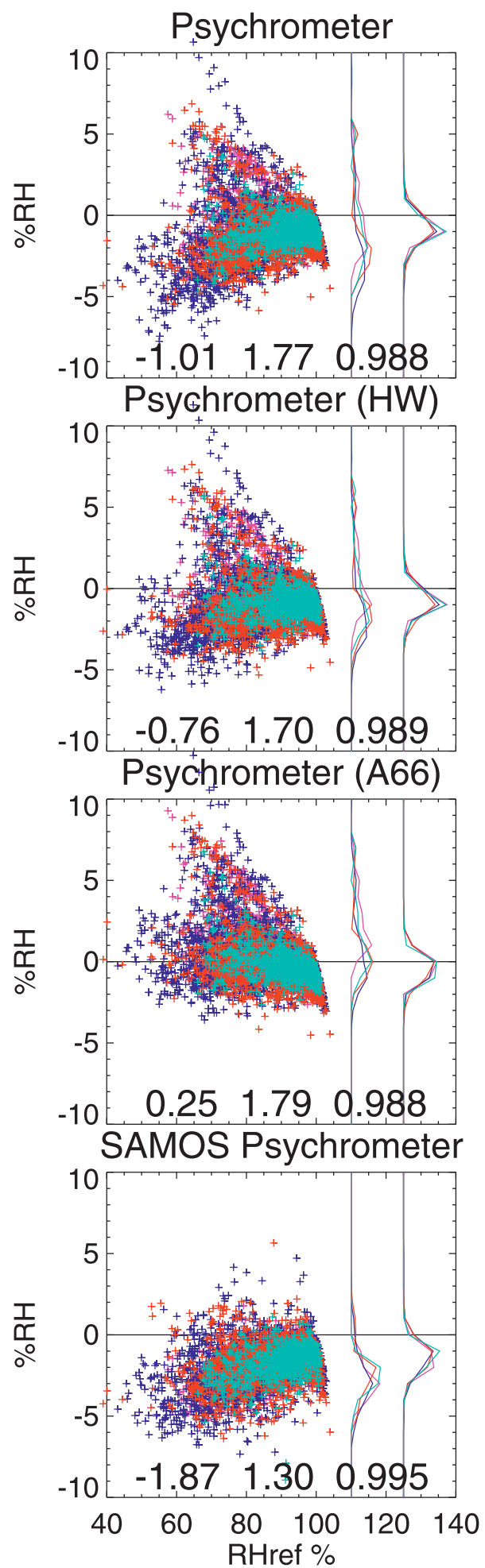

26Jan-3Mar

4Mar-16May
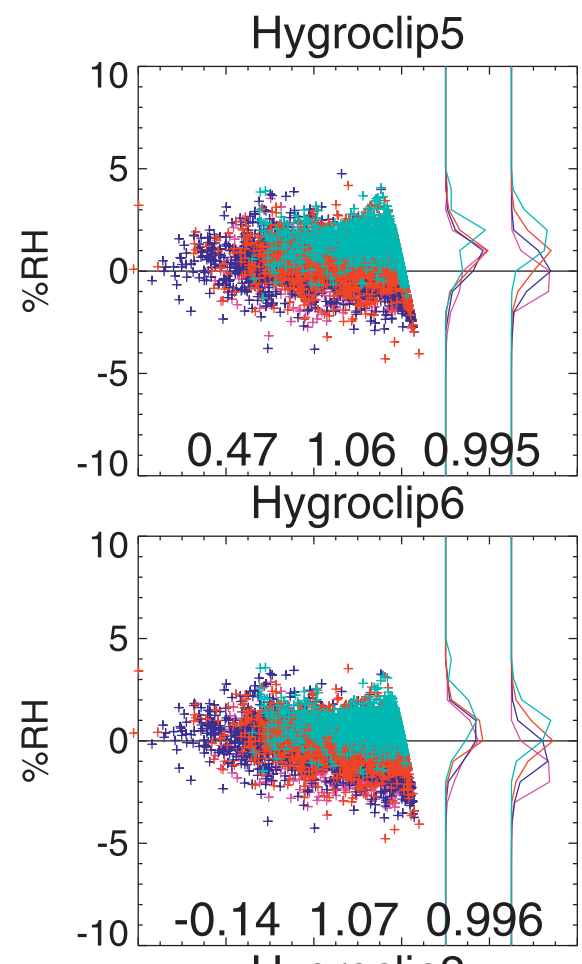

Hygroclip2
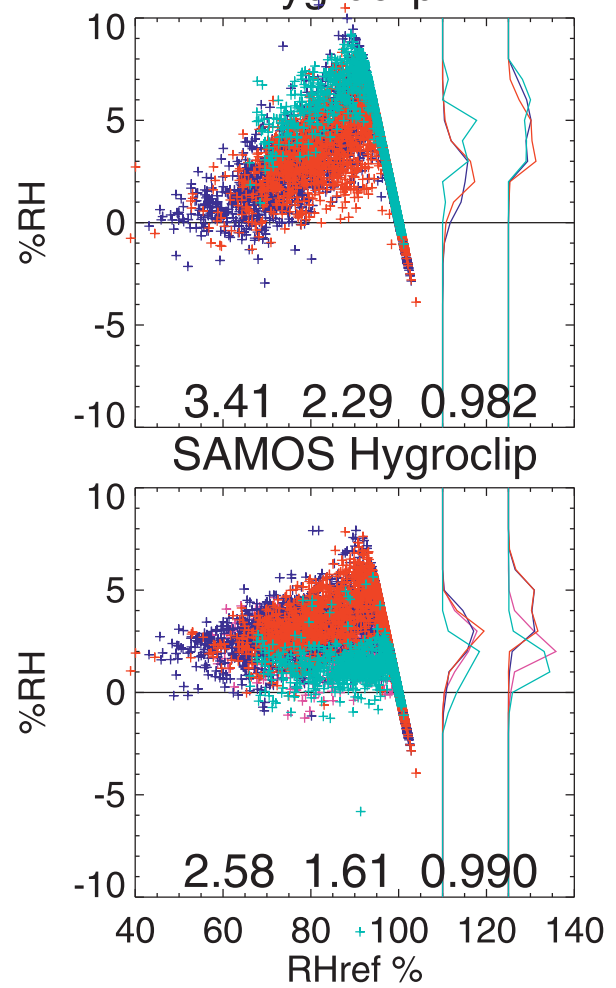

17May-30Jul 30Jul-3Sep

FIG. 5. Scatterplots of hourly averages of test instrument minus RHref (mean of Thygan RH) vs RHref. Data are for 25 Jan-3 Sep 2008 except for HygroClip2, which started on 3 Mar. Color coding as in key at bottom. Bolded numbers are the mean and SD of the difference and the correlation between the test RH and RHref (hourly mean values) over the whole period, respectively. Two lines at the right-hand side of each panel are the frequency distribution of the difference calculated for RHref of $70 \% \pm 2.5 \% \mathrm{RH}$ and $95 \% \pm$ $2.5 \% \mathrm{RH}$ (offsets of 110 and 125 used for figure). See text for further details. 
TABLE 4. Comparison (\% RH) of various instruments with the mean Thygan RH (RHref) for the period 25 Jan-3 Sept 2008 except for HygroClips1 and 2, which started on $3 \mathrm{March} ; N$ is the number of samples, bias and SD are for (RH - RHref), and corr is the correlation between RH and RHref. Slope is a regression estimate of the change in \% RH relative to the reference over a year but not given for the SAMOS HygroClip because of the change of instrument. Bias and slope are only given for the 10-min data, as they are almost identical for the hourly data.

\begin{tabular}{|c|c|c|c|c|c|c|c|c|}
\hline \multirow[b]{2}{*}{ Instrument } & \multicolumn{5}{|c|}{ 10-min data } & \multicolumn{3}{|c|}{ Hourly data } \\
\hline & $N$ & Bias & SD & Corr & Slope & $N$ & SD & Corr \\
\hline Psychrometer & 29671 & -1.01 & 2.25 & 0.981 & -0.94 & 4960 & 1.77 & 0.988 \\
\hline Psychrometer HW & 29671 & -0.76 & 2.20 & 0.981 & -1.39 & 4960 & 1.70 & 0.989 \\
\hline Psychrometer A66 & 29671 & 0.25 & 2.25 & 0.981 & -2.65 & 4960 & 1.79 & 0.988 \\
\hline SAMOS psychrometer & 29671 & -1.87 & 2.08 & 0.985 & 0.45 & 4960 & 1.30 & 0.995 \\
\hline SAMOS HygroClip & 29671 & 2.58 & 2.02 & 0.984 & - & 4960 & 1.61 & 0.990 \\
\hline HygroClip1 & 24476 & 2.62 & 2.98 & 0.972 & 9.91 & 4091 & 2.58 & 0.980 \\
\hline HygroClip2 & 24476 & 3.41 & 2.74 & 0.974 & 4.40 & 4091 & 2.29 & 0.982 \\
\hline HygroClip4 & 29671 & 1.06 & 1.77 & 0.988 & 1.98 & 4960 & 1.08 & 0.995 \\
\hline HygroClip5 & 29671 & 0.47 & 1.76 & 0.988 & 2.20 & 4960 & 1.06 & 0.995 \\
\hline HygroClip6 & 29671 & -0.14 & 1.76 & 0.988 & 2.38 & 4960 & 1.07 & 0.996 \\
\hline
\end{tabular}

scatterplots of various instruments against the average of the RH from the two Thygans (RHref). Both Figs. 4 and 5 use hourly averages (with at least four values per hour); the 10-min data have similar general behavior but more scatter-Table 4 summarizes statistics for both 10 -min and hourly data. The psychrometers tend to have their largest scatter at about $60 \%-80 \% \mathrm{RH}$, and they tend to be biased dry at lower humidities. The psychrometer, psychrometer HW, and psychrometer A66 in Fig. 5 and the appendix tables all use $T_{w}$ from the trial psychrometer but the coefficient $A$ for each is given by 0.000799 (the operational value), $A_{\text {eff }}$ from the Harrison and Wood (2012) formula [Eq. (4)], and 0.000666 , respectively. The bias is lowest for psychrometer A66, the value recommended for aspirated psychrometers (Table 3). ${ }^{5}$ Figure 5 suggests that when large psychrometer errors occur, they are mostly positive. The best HygroClips, 5 and 6, perform slightly better than the psychrometers. The worst, HygroClip2, which had been withdrawn from another station because of suspect performance, has a positive bias of $3.4 \% \mathrm{RH}$, being worst at high $\mathrm{RH}$ and toward the end of the trial. The SAMOS instruments have larger biases than most of the trial instruments, with the RH sensor on average $4.5 \%$ RH wetter than the SAMOS psychrometer (Table 4). The appendix provides detailed daytime statistics from this trial.

\footnotetext{
${ }^{5}$ It is not clear if the various changes to the psychrometer (section 3a) changed the required value of $A$ or if $A=0.000799$ was originally too high. Wylie and Lalas (1992) reported that the traditional value of $A$ for reference psychrometers was too high. Section 4.2.3 of WMO (2010) discusses the uncertainty in $A$.
}

\section{e. 2011-12 Camborne trial: Description and results}

In 2011 another trial was started at Camborne to examine the long-term performance of heated capacitive sensors. There was one Thygan operating-its mirror was automatically cleaned each day. The outputs were recorded every minute. The Thygan failed on 24 May 2012; it was replaced by another Thygan but only after a gap of almost three months. There were two Vaisala HMP110 unheated humidity sensors and four Vaisala HMP155 heated humidity and temperature sensors in the trial. The instruments were deployed in January 2011; results are shown from 9 April 2011 after initial problems with the site cabling and power supply had been resolved. Two HMP155 sensors had connection problems early in the trial—data from these two sensors are only shown in the time series. Data every minute from the MMS thermometer, psychrometer, and HygroClip sensor were also processed.

Figures $6 \mathrm{a}-\mathrm{c}$ show extended episodes of saturation from early 2012. "Thygan-PRT RH" (=RHref) uses the Thygan dewpoint and a screen PRT temperature as for 2008. "Thygan RH" (output from the instrument using the Thygan temperature to give saturation humidity) was generally too low because the Thygan temperature was too high. (A Thygan unit has been tested in the calibration chamber; where the dewpoint temperature was found to be reasonably accurate but the air temperature was less accurate.) The other RHs show good agreement, but during the periods when the other sensors are showing saturation (and there was rain/drizzle or mist noted in the SYNOP reports), the Thygan-PRT $\mathrm{RH}$ can be either $1 \%$ or $2 \%$ RH higher or lower (in mist/ cloud, the measured Thygan dewpoint is sensitive to the inlet used and any heating applied, which could convert water droplets to vapor). For the cases shown in Figs. 6a 
a) Relative Humidity, 20-21 January 2012

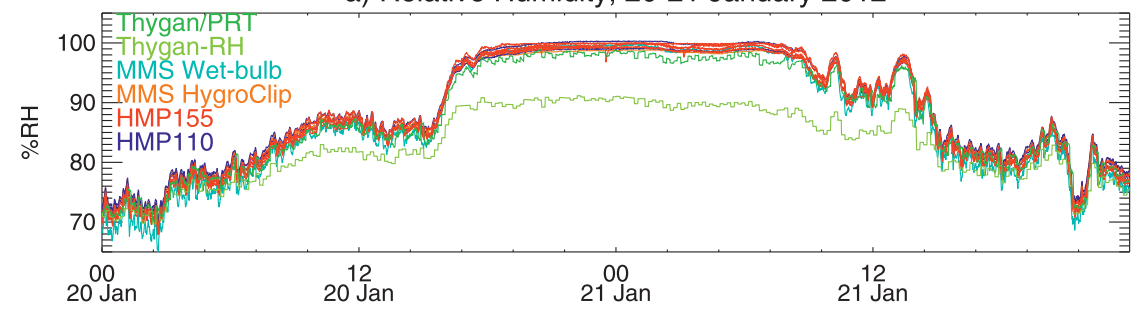

b) Relative Humidity, 22-23 February 2012

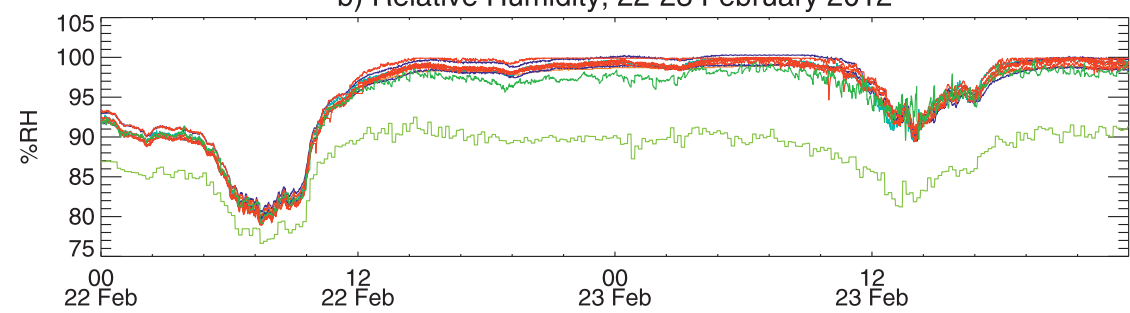

c) Relative Humidity, 12-14 March 2012

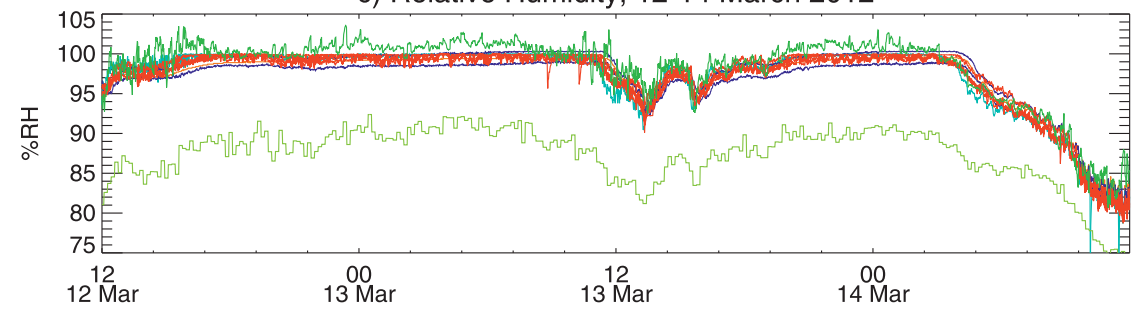

d) Relative Humidity, 1 February 2012

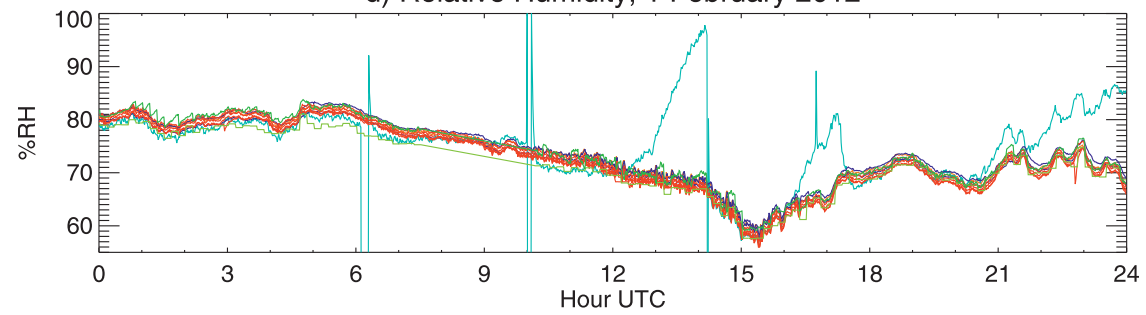

e) Temperature, 1 February 2012

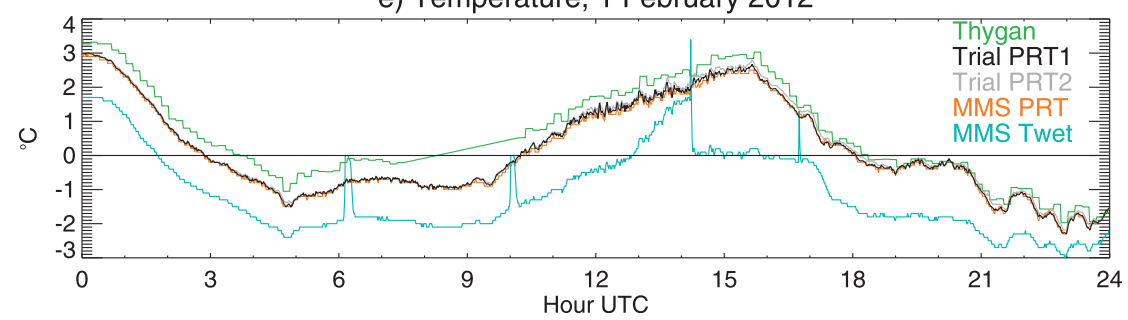

FIG. 6. (a)-(d) RH time series (1-min data) for various dates (all times UTC). Key in (a) gives color coding. In (d) there was a Thygan reboot between about 0730 and 1000 UTC. (e) Temperature time series $\left({ }^{\circ} \mathrm{C}\right)$ colors as given at right-hand side.

and $6 \mathrm{~b}$-with reference RH slightly below saturationthe wind speed was about $10 \mathrm{~m} \mathrm{~s}^{-1}$; for the case in Fig. $6 \mathrm{c}$-with reference RH slightly above saturation-the wind speed was $2-4 \mathrm{~m} \mathrm{~s}^{-1}$.

Figures $6 \mathrm{~d}$ and $6 \mathrm{e}$ show $\mathrm{RH}$ and temperature from a period of freezing weather. The psychrometer recorded some erroneous RH values on 1 February 2012. The temporary rise of the wet-bulb temperature to $0^{\circ} \mathrm{C}$ just after 0600 UTC might be due to latent heat release; there was a second event just after 1000 UTC-these events were flagged by the MMS software. Over the following 60 hours, other problems occurred-mainly, 
a) Mean Reference $\mathrm{RH}$

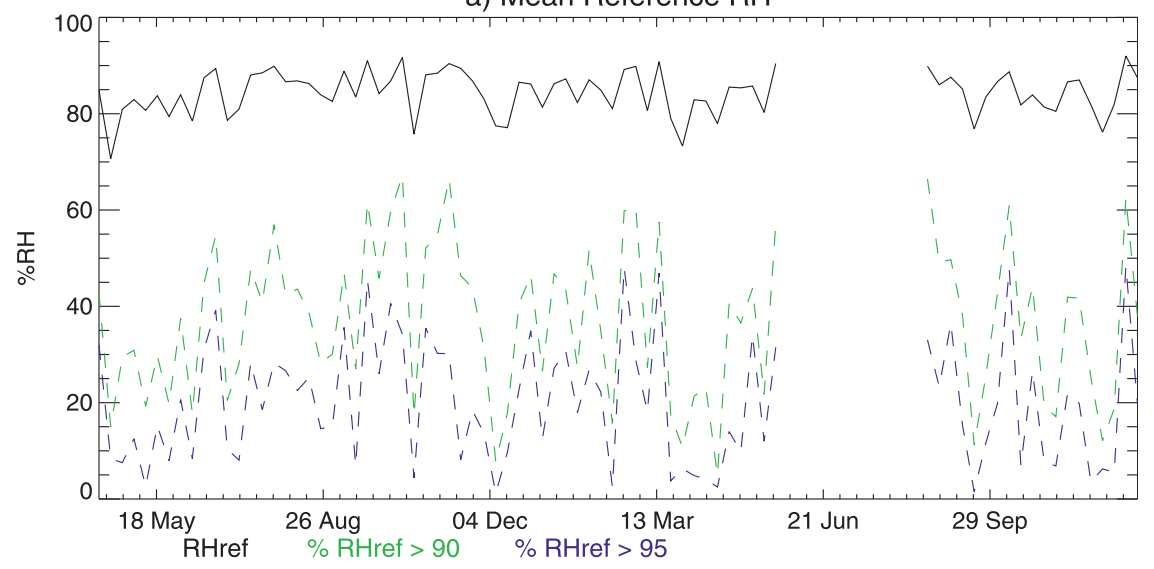

b) Relative Humidity mean difference

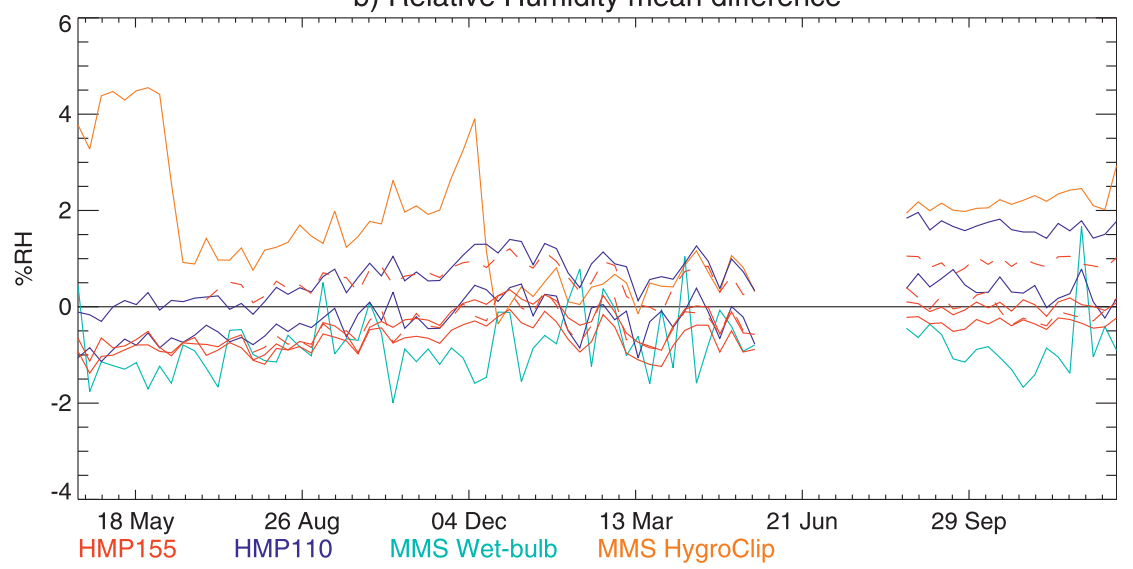

c) Relative Humidity SD of difference

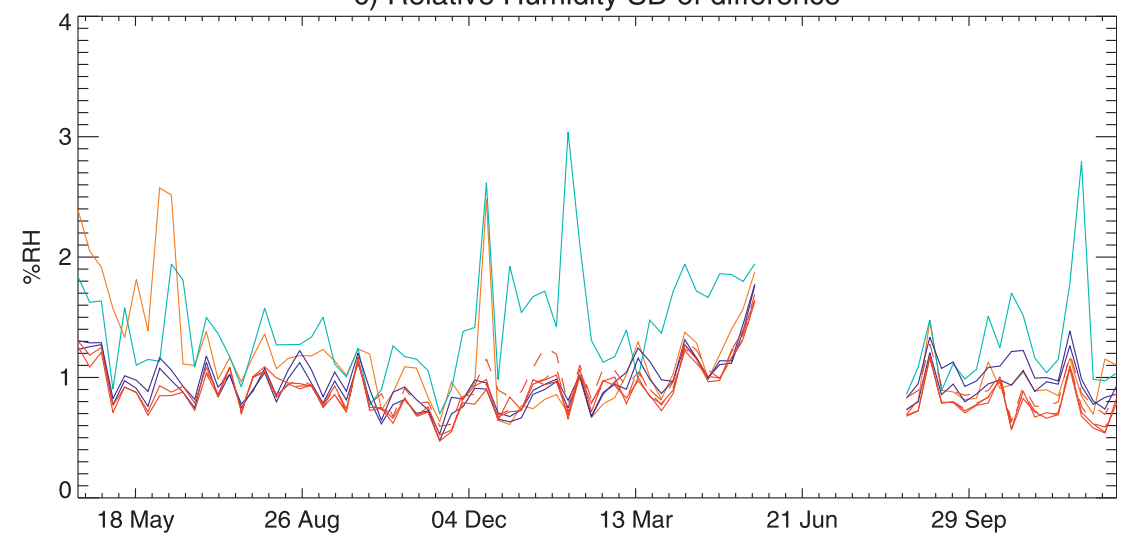

FIG. 7. As in Fig. 2, but for 9 Apr 2011-31 Dec 2012. (b),(c) Line colors as in key (dashed red lines for the HMP155 sensors with connector problems for part of the trial). Note that the sensors were initially deployed in January 2011 and that the statistics are for those minutes when the Thygan has just been updated (mainly affects the SD).

the RH values were too high (as seen 1200-1400, around 1700, and 2200-2400 UTC in Fig. 6d). These are probably symptoms of insufficient water flow up the wick because of ice formation, and in general they were not flagged by the MMS software.
For the statistics below a small proportion of values was excluded for various reasons: times of Thygan reboots and 42 samples when one of the HMP155 instruments gave negative humidities. For the MMS data, the exclusions were 1) $12 \mathrm{~h}$ each on 9 June and 
TABLE 5. Comparison with the Thygan RH April 2011-April 2012 (columns as in Table 4). MMS HygroClip was replaced twice. Thygan reading is updated approximately every $10 \mathrm{~min}$; only the "update minutes" have been used in the statistics, either individually or combined into hourly averages.

\begin{tabular}{|c|c|c|c|c|c|c|c|c|}
\hline \multirow[b]{2}{*}{ Instrument } & \multicolumn{5}{|c|}{ Thygan update data } & \multicolumn{3}{|c|}{ Hourly data } \\
\hline & $N$ & Bias & SD & Corr & Slope & $N$ & SD & Corr \\
\hline MMS psychrometer & 55024 & -0.83 & 1.60 & 0.993 & 0.53 & 9154 & 1.40 & 0.995 \\
\hline MMS HygroClip & 55024 & 1.64 & 1.86 & 0.986 & - & 9154 & 1.71 & 0.988 \\
\hline HMP110-1 & 55579 & -0.33 & 1.06 & 0.996 & 0.80 & 9154 & 0.82 & 0.998 \\
\hline HMP110-2 & 55579 & 0.56 & 1.03 & 0.996 & 1.11 & 9154 & 0.78 & 0.998 \\
\hline HMP155-1 & 55579 & -0.45 & 0.99 & 0.997 & 0.83 & 9154 & 0.79 & 0.998 \\
\hline HMP155-4 & 55579 & -0.71 & 0.95 & 0.997 & 0.42 & 9154 & 0.73 & 0.998 \\
\hline
\end{tabular}

14 December 2011 when the HygroClip was replaced; 2) 1-3 February 2012, the freezing cases previously discussed; and 3) cases where the MMS psychrometer RH (subject to occasional spikes) differed by more than $15 \%$ RH from the HygroClip RH. HygroClip values recorded as $100.5 \% \mathrm{RH}$ were reset to $100 \% \mathrm{RH}$ to match operational reporting practice. Once a day the HMP155s were automatically purged: the sensor was strongly heated for 4 min to drive off any chemical contamination. During the purge and for $13 \mathrm{~min}$ afterward, the last $\mathrm{RH}$ observation from just before the purge is reported-these values have been used in the statistics.

Figure 7 shows week-by-week bias and SD of the various sensors compared to the reference $\mathrm{RH}$, and Table 5 tabulates some overall statistics (this and Table 6 show statistics up to the end of April 2012). In Fig. 7b the clearest features are the two replacements of the MMS HygroClip (orange), which also give rise to peaks in the SD (Fig. 7c). Coincidentally, the psychrometer (light blue) also has peaks in the SD on these weeks (there were problems with a new wick on 11 June but for the week around 14 December, any psychrometer problems are less clear; the lowest wet-bulb temperatures then were around $3^{\circ} \mathrm{C}$ ). Each MMS HygroClip instrument shows an upward trend, but the last two perform well in terms of SD. The psychrometer has a larger SD than usual between December 2011 and April 2012 and a less negative bias-although observations from 1 to 3 February with the worst problems (Fig. 6d) were excluded from the statistics in Fig. 7. The Vaisala sensors perform well: the unheated sensors (blue) show a trend of about 1\% RH over the year to April 2012 and the heated sensors (red) about $0.6 \% \mathrm{RH}$; in the first five months of 2012 the biases seemed to have leveled off, and the later data suggest some increase in bias for the unheated sensors but little, if any, for the heated ones. The diurnal variation (Fig. S6 in supplemental material) is slightly less marked than in Fig. 3.

Figure 8 shows scatterplots for hourly average data. The MMS psychrometer and HygroClip results are consistent with those in Fig. 5. As before the psychrometer errors show a positive skewness that was probably due to cases with insufficient flow to the wet bulb. The Vaisala scatterplots show a good performance; at lower RH the unheated HMP110 RHs are slightly high on average and the heated HMP155 RHs are slightly low (the capacitive element is the same for both instruments). The statistics in Figs. 7 and 8 and Table 5 are produced using only observations from those minutes when the Thygan dewpoint has been updated. Similar statistics using observations from all minutes give very similar biases and worse SDs (Table 6) because the RHref can be up to nine minutes old. The 2008 SDs (Table 4) would presumably have been smaller if the data points had been synchronized with the Thygan updates in 2008.

\section{Summary}

Humidity is difficult to measure accurately and even the reference chilled mirror instruments have nonnegligible errors under some conditions. Sensors can suffer to various extents from contamination: from dust on a mirror, from pollutants like $\mathrm{SO}_{2}$, or from water within the material under test when the assumption is that water only forms a surface layer. Results from two field comparisons in the United Kingdom have been presented - they illustrate various practical issues/errors. Previous field comparisons and theoretical studies have been summarized (this is hampered by the multiplicity of terms for humidity instruments and the proportion of studies that have not been peer reviewed).

TABLE 6. As in Table 5, but for data sampled every minute.

\begin{tabular}{lcrcc}
\hline \hline \multicolumn{1}{c}{ Instrument } & $N$ & \multicolumn{1}{c}{ Bias } & SD & Corr \\
\hline MMS psychrometer & 550319 & -0.83 & 2.01 & 0.987 \\
MMS HygroClip & 550319 & 1.63 & 2.19 & 0.980 \\
HMP110-1 & 555820 & -0.33 & 1.57 & 0.990 \\
HMP110-2 & 555820 & 0.56 & 1.55 & 0.990 \\
HMP155-1 & 555820 & -0.46 & 1.51 & 0.992 \\
HMP155-4 & 555820 & -0.72 & 1.49 & 0.992 \\
\hline
\end{tabular}



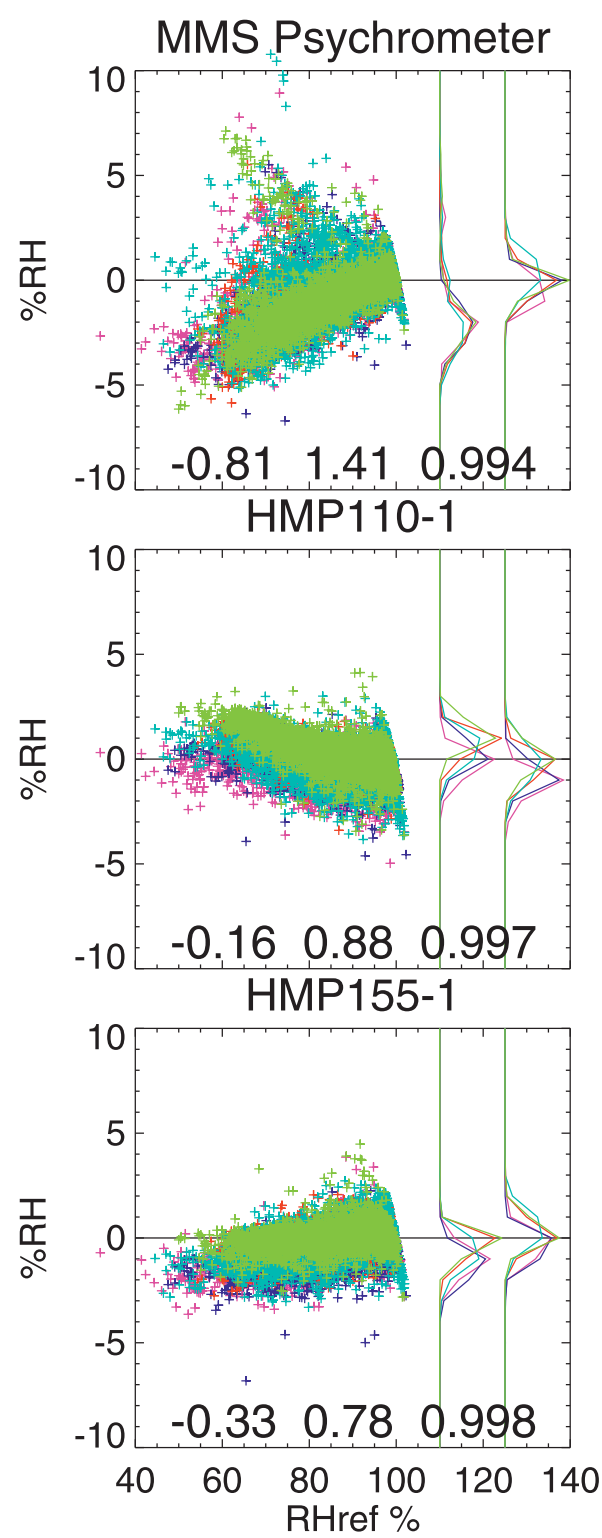
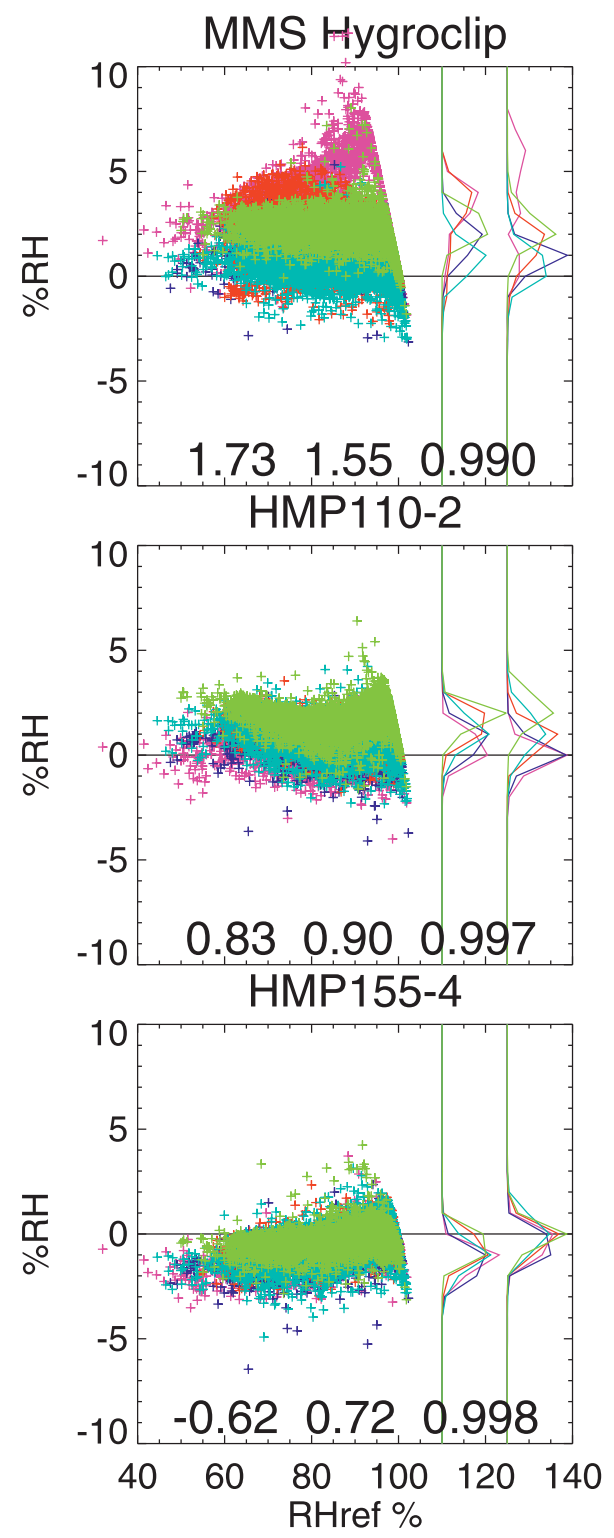

9Apr-23Jun11 24Jun-30Sep11 1Oct-31Dec11 1Jan-23May12 23Aug-31Dec12

FIG. 8. As in Fig. 5, but for 2011-12 trial; color coded as in key.

Well-installed and maintained psychrometers usually perform well, particularly at high relative humidities (any problems with the wick or the psychrometer coefficient are less important at high $\mathrm{RH}$ ). In the trials they showed some week-to-week variability (probably because of wick problems) and worse performance in winter but without longer-term trends. Psychrometers are difficult to operate well, particularly in freezing conditions. If the wet bulb partially dries out, then the derived RH is too high. Psychrometers are based on well-known physical principles, but the psychrometer coefficient depends on the details of the instrument. The coefficient used by the Met Office seems to be too high for current instruments, giving humidities that are too low at lower RH. Apart from Lucas (2010), no documentation was found of the performance of other operational psychrometers. The results here highlight the need for operational details to be openly available.

Capacitive sensors generally perform well when new, usually slightly better than the operational psychrometers. In arid conditions the good performance tends to continue but in wetter climates there is a drift, so that at high $\mathrm{RH}$ they report too high a value. The drift, found in other studies as well, is typically $1 \%-2 \% \mathrm{RH} \mathrm{yr}^{-1}$ but can be between about $0 \%$ and $5 \% \mathrm{RH} \mathrm{yr}{ }^{-1}$. Capacitive sensors rely on an experimentally determined relationship 
TABLE A1. Mean and SD differences (RH - RHref, \% RH) for core daylight hours (0900-1750 UTC, data points every 10 min) for psychrometer and selected HygroClips, stratified by wind speed.

\begin{tabular}{|c|c|c|c|c|c|c|c|c|}
\hline \multirow{4}{*}{$\begin{array}{l}\text { Wind speed range }\left(\mathrm{m} \mathrm{s}^{-1}\right) \\
\text { No. of points } \\
\text { Mean RHref } \\
\text { Instrument }\end{array}$} & \multicolumn{2}{|c|}{$0-2$} & \multicolumn{2}{|c|}{$2-5$} & \multicolumn{2}{|c|}{$5-8$} & \multicolumn{2}{|c|}{$>8$} \\
\hline & \multicolumn{2}{|c|}{237} & \multirow{2}{*}{\multicolumn{2}{|c|}{$\begin{array}{l}3595 \\
82.61\end{array}$}} & \multirow{2}{*}{\multicolumn{2}{|c|}{$\begin{array}{l}4864 \\
79.18\end{array}$}} & \multirow{2}{*}{\multicolumn{2}{|c|}{$\begin{array}{l}2422 \\
79.51\end{array}$}} \\
\hline & & & & & & & & \\
\hline & Mean & SD & Mean & $\mathrm{SD}$ & Mean & SD & Mean & SD \\
\hline Psychrometer & -0.68 & 2.19 & -1.31 & 2.51 & -1.24 & 2.90 & -1.48 & 2.95 \\
\hline Psychrometer HW & -1.94 & 2.41 & -1.24 & 2.51 & -0.63 & 2.85 & -0.71 & 2.82 \\
\hline Psychrometer A66 & 0.78 & 2.36 & 0.14 & 2.56 & 0.47 & 2.85 & 0.31 & 2.79 \\
\hline SAMOS psychrometer & -1.35 & 2.88 & -2.05 & 2.56 & -2.51 & 2.51 & -2.38 & 2.43 \\
\hline HygroClip2 & 1.52 & 3.45 & 2.72 & 3.17 & 2.69 & 2.94 & 2.69 & 2.90 \\
\hline HygroClip4 & 0.13 & 2.15 & 0.61 & 2.22 & 0.96 & 2.07 & 1.18 & 2.04 \\
\hline HygroClip5 & -0.45 & 2.15 & 0.09 & 2.22 & 0.46 & 2.06 & 0.64 & 2.03 \\
\hline HygroClip6 & -0.96 & 2.06 & -0.46 & 2.21 & -0.02 & 2.06 & 0.17 & 2.01 \\
\hline
\end{tabular}

between capacitance and RH (this can give supersaturated measurements but in practice such values are reset to $100 \% \mathrm{RH}$; without this limit the errors would be worse at high $\mathrm{RH}$ ). They work best when there is little moisture to change their dielectric properties, that is, at low RH. Their reaction time is longest near saturation and at low temperatures. The effects of aging/contamination can be addressed by frequent readjustment, recalibration, and replacement of sensors. The heated sensors tested in the 2011-12 trial showed less drift; they are more expensive, but this cost might be offset by less need for readjustment and recalibration. Future work in the United Kingdom includes regional deployment of chilled mirror hygrometers and attempts to use these to improve the analysis of screen-level $\mathrm{RH}$ fields.

In the United Kingdom, the replacement of psychrometers by capacitive sensors (mainly in 2008-09) seems to have replaced a dry bias with a wet bias (from approximately $-1 \%$ to $1.5 \%-2 \% \mathrm{RH}$ but capacitive sensor bias is quite variable). This change in bias is potentially important for climate change studies, especially if it is found to apply to other countries as well. As observing has been automated, various other countries have also changed from psychrometers to capacitive sensors. However, for many countries there is no direct evidence of which types of humidity instrument are used. The new WMO table-driven code templates should be improved to indicate whether the system is aspirated, heated, and the type of humidity instrument used.

An uncertainty of $2 \%-3 \%$ RH may be achieved by operational instruments under the best conditions (not meeting the $1 \% \mathrm{RH}$ requirement), but it is likely that typical uncertainty is somewhat worse. For naturally ventilated screens, used for most measurements, errors may be larger in calm conditions. Relative humidity natural variability and errors are somewhat larger during daylight hours than at night.

Acknowledgments. Robert Dunn was supported by the Joint DECC and Defra Integrated Climate Programme (GA01101). We wish to thank Mike Molyneux, Rick Rawlins, David Parker, Kate Willett, and Neil Mander for support and/or comments on the manuscript, and three anonymous reviewers for their useful comments.

TABLE A2. As in Table A1, but stratified by screen temperature.

\begin{tabular}{|c|c|c|c|c|c|c|c|c|}
\hline \multirow{4}{*}{$\begin{array}{c}\text { Temperature range }\left({ }^{\circ} \mathrm{C}\right) \\
\text { No. of points } \\
\text { Mean RHref } \\
\text { Instrument }\end{array}$} & \multicolumn{2}{|c|}{$0-8$} & \multicolumn{2}{|c|}{$8-12$} & \multicolumn{2}{|c|}{$12-16$} & \multicolumn{2}{|c|}{$>16$} \\
\hline & \multicolumn{2}{|c|}{1175} & \multicolumn{2}{|c|}{3697} & \multicolumn{2}{|c|}{3492} & \multicolumn{2}{|c|}{2754} \\
\hline & \multicolumn{2}{|c|}{74.79} & \multicolumn{2}{|c|}{80.88} & \multicolumn{2}{|c|}{82.96} & \multicolumn{2}{|c|}{79.05} \\
\hline & Mean & SD & Mean & SD & Mean & SD & Mean & SD \\
\hline Psychrometer & -1.49 & 3.67 & -0.71 & 2.89 & -1.70 & 2.43 & -1.51 & 2.44 \\
\hline Psychrometer HW & -0.81 & 3.50 & -0.27 & 2.87 & -1.36 & 2.44 & -1.10 & 2.40 \\
\hline Psychrometer A66 & 0.99 & 3.20 & 0.99 & 2.93 & -0.31 & 2.45 & -0.00 & 2.31 \\
\hline SAMOS psychrometer & -2.84 & 2.72 & -2.11 & 2.44 & -2.33 & 2.56 & -2.32 & 2.49 \\
\hline HygroClip2 & 0.86 & 2.64 & 1.65 & 2.82 & 3.21 & 2.73 & 4.16 & 2.90 \\
\hline HygroClip4 & 0.44 & 2.33 & 0.62 & 1.98 & 0.89 & 2.12 & 1.41 & 2.14 \\
\hline HygroClip5 & -0.05 & 2.33 & 0.04 & 1.97 & 0.37 & 2.11 & 0.95 & 2.11 \\
\hline HygroClip6 & -0.56 & 2.33 & -0.50 & 1.99 & -0.13 & 2.09 & 0.50 & 2.05 \\
\hline
\end{tabular}


TABLE A3. As in Table A1, but stratified by RHref.

\begin{tabular}{|c|c|c|c|c|c|c|c|c|}
\hline \multirow{2}{*}{$\begin{array}{c}\text { RHref range }(\% \mathrm{RH}) \\
\text { No. of points } \\
\text { Mean RHref } \\
\text { Instrument }\end{array}$} & \multicolumn{2}{|c|}{$\begin{array}{c}<50 \\
65 \\
46.00 \\
\end{array}$} & \multicolumn{2}{|c|}{$\begin{array}{c}50-70 \\
1929 \\
64.24\end{array}$} & \multicolumn{2}{|c|}{$\begin{array}{c}70-90 \\
6557 \\
79.57 \\
\end{array}$} & \multicolumn{2}{|c|}{$\begin{array}{l}>90 \\
2567 \\
95.69\end{array}$} \\
\hline & Mean & SD & Mean & SD & Mean & SD & Mean & SD \\
\hline Psychrometer & -2.54 & 2.74 & -1.19 & 3.98 & -1.30 & 2.72 & -1.38 & 1.57 \\
\hline Psychrometer HW & -1.22 & 2.73 & -0.33 & 3.86 & -0.87 & 2.69 & -1.29 & 1.55 \\
\hline Psychrometer A66 & 1.73 & 2.52 & 1.82 & 3.62 & 0.39 & 2.57 & -0.94 & 1.50 \\
\hline SAMOS psychrometer & -3.00 & 2.13 & -2.56 & 2.98 & -2.41 & 2.56 & -1.85 & 1.98 \\
\hline HygroClip2 & 1.26 & 2.66 & 1.79 & 2.93 & 2.90 & 3.08 & 2.81 & 2.83 \\
\hline HygroClip4 & 1.35 & 2.65 & 1.21 & 2.62 & 0.86 & 2.11 & 0.66 & 1.65 \\
\hline HygroClip5 & 1.35 & 2.61 & 0.91 & 2.58 & 0.32 & 2.09 & 0.04 & 1.68 \\
\hline HygroClip6 & 1.51 & 2.57 & 0.71 & 2.52 & -0.21 & 2.05 & -0.64 & 1.67 \\
\hline
\end{tabular}

\section{APPENDIX}

\section{Detailed Daytime Statistics}

Tables A1-A3 show differences from RHref as a function of wind speed, temperature, and RHref, respectively, from the 2008 trial (section 3d). The statistics have been restricted to 0900-1750 UTC (local noon is 1221 UTC) because all three variables have a clear day/night signal (Fig. 3) that might otherwise dominate the comparison. The trial psychrometer (with RH calculated in various ways) has the largest SD at high wind speed (Table A1) and the SAMOS psychrometer has the largest SD at low wind speed, which is what was expected. For the HygroClips the bias tends to become more positive at higher wind speed and, if anything, the SD decreases slightly. For temperature (Table A2) the clearest signal is that the psychrometers have a larger SD at lower temperatures. The psychrometers have the lowest SD for RHref $>90 \% \mathrm{RH}$ (Table A3) and the highest for $50 \%-70 \% \mathrm{RH}$ (the sample with RHref $<50 \% \mathrm{RH}$ is rather small). The HygroClips also have their lowest SD for RHref $>90 \% \mathrm{RH}$, helped by the truncation at $100 \%$ RH. The biases [test instrument RH (RHtest) - RHref] in the lowest/highest categories in Table A3 may be partly an effect of basing the categories on RHref because RHref is also subject to some errors. If the true value of RH is close to the $90 \% \mathrm{RH}$ category boundary, then RHref values with positive errors will tend to fall in the top category, whereas RHref values with negative errors will not, giving a slight positive bias to RHref values in the top category. In a similar way, the lowest category will have a slight negative bias of RHref. (If RHtest and RHref had the same error distribution, then using the mean of RHtest and RHref for the categories would give unbiased sampling; however, the RHref errors are smaller, which is why we use it as the reference.)

\section{REFERENCES}

Anderson, P. S., 1995: Mechanism for the behavior of hydroactive materials used in humidity sensors. J. Atmos. Oceanic Technol., 12, 662-667.

Baker, R., R. Curtis, D. Helms, A. Homans, and B. L. Ford, 2011: Studies of the effectiveness of the water vapor sensing system, WVSS-II, in supporting airline operations and improved air traffic capacity. Preprints, Second Aviation, Range, and Aerospace Meteorology Special Symp. on Weather-Air Traffic Management Integration, Seattle, WA, Amer. Meteor. Soc., P1.335. [Available online at https://ams.confex.com/ams/ 91Annual/webprogram/Paper181457.html.]

Burt, S., 2012: Weather Observer's Handbook. Cambridge University Press, 444 pp.

Clark, P. A., S. A. Harcourt, B. Macpherson, C. T. Mathison, S. Cusack, and M. Naylor, 2008: Prediction of visibility and aerosol within the operational Met Office Unified Model. I: Model formulation and variational assimilation. Quart. J. Roy. Meteor. Soc., 134, 1801-1816, doi:10.1002/qj.318.

Dai, A., 2006: Recent climatology, variability, and trends in global surface humidity. J. Climate, 19, 3589-3606.

_ J. Wang, P. W. Thorne, D. E. Parker, L. Haimberger, and X. L. Wang, 2011: A new approach to homogenize daily radiosonde humidity data. J. Climate, 24, 965-991.

Dery, S. J., and M. Stieglitz, 2002: A note on surface humidity measurements in the cold Canadian environment. Bound.Layer Meteor., 102, 491-497.

Dharssi, I., K. J. Bovis, B. Macpherson, and C. P. Jones, 2011: Operational assimilation of ASCAT surface soil wetness at the Met Office. Hydrol. Earth Syst. Sci., 15, 2729-2746, doi:10.5194/hess-15-2729-2011.

Gaffen, D. J., and R. J. Ross, 1999: Climatology and trends of U.S. surface humidity and temperature. J. Climate, 12, 811828.

Gao, F., X. Zhang, N. Jacobs, X. Huang, X. Zhang, and P. Childs, 2012: Estimation of TAMDAR observational error and assimilation experiments. Wea. Forecasting, 27, 856-877.

Green, A., 2010: From observations to forecasts-Part 7. A new meteorological monitoring system for the United Kingdom's Met Office. Weather, 65, 272-277, doi:10.1002/ wea.649.

Harrison, R. G., and C. R. Wood, 2012: Ventilation effects on humidity measurements in thermometer screens. Quart. J. Roy. Meteor. Soc., 138, 1114-1120, doi:10.1002/qj.985. 
Ingleby, B., 2010: Factors affecting ship and buoy data quality: A data assimilation perspective. J. Atmos. Oceanic Technol., 27, 1476-1489.

—, A. C. Lorenc, K. Ngan, F. Rawlins, and D. R. Jackson, 2013: Improved variational analyses using a nonlinear humidity control variable. Quart. J. Roy. Meteor. Soc., doi:10.1002/ qj.2073, in press.

Jelinek, K., J. M. Pernter, and J. von Hann, 1903: Jelineks Psychrometer-Tafeln. 5th ed. W. Engelmann, 107 pp.

Lacombe M., D. Bousri, M. Leroy, M. Mezred, 2011: WMO field intercomparison of thermometer screens/shields and humidity measuring instruments: Ghardaïa, Algeria, November 2008October 2009. WMO/TD-1579, IOM Rep. 106, 101 pp. [Available online at http://www.wmo.int/pages/prog/www/IMOP/ publications-IOM-series.html.]

Lin, X., and K. G. Hubbard, 2004: Uncertainties of derived dewpoint temperature and relative humidity. J. Appl. Meteor., 43, 821-825.

Loescher, H. W., C. V. Hanson, and T. W. Ocheltree, 2009: The psychrometric constant is not constant: A novel approach to enhance the accuracy and precision of latent energy fluxes through automated water vapor calibrations. J. Hydrometeor., 10, 1271-1284.

Lucas, C., 2010: A high-quality historical humidity database for Australia. CAWCR Tech. Rep. 024, 176 pp. [Available online at http://www.cawcr.gov.au/publications/technicalreports/ CTR_024.pdf.]

Makkonen, L., and T. Laakso, 2005: Humidity measurements in cold and humid environments. Bound.-Layer Meteor., 116, 131-147.

Met Office, 1981: Measurement of Humidity. Vol. 3, Handbook of Meteorological Instruments, 2nd ed. HMSO, $60 \mathrm{pp}$.

— 1982: Observer's Handbook. 4th ed. HMSO, 220 pp. [Available online at http://www.metoffice.gov.uk/archive/observershandbook-4th-edition-reprint.]

_ 2009: SPOT-ON Observers Guide. Version 4, Met Office, 137 pp.

Miloshevich, L. M., H. Vömel, D. N. Whiteman, and T. Leblanc, 2009: Accuracy assessment and correction of Vaisala RS92 radiosonde water vapor measurements. J. Geophys. Res., 114, D11305, doi:10.1029/2008JD011565.

Moninger, W. R., S. G. Benjamin, B. D. Jamison, T. W. Schlatter, T. Orrainesmith, and A. S. Zoke, 2010: Evaluation of regional aircraft observations using TAMDAR. Wea. Forecasting, 25, $627-645$.

NWS, 2002: ASOS product improvement implementation plan for dew point sensor upgrade. NOAA Rep., 50 pp. [Available online at http://www.nws.noaa.gov/ops2/Surface/documents/ DewPoint0816.pdf.]

Pang, S., H. Graßl, and H. Jäger, 1996: An improved humidity sensor. J. Atmos. Oceanic Technol., 13, 1110-1115.

Perry, M. C., M. J. Prior, and D. E. Parker, 2007: An assessment of the suitability of a plastic thermometer screen for climatic data collection. Int. J. Climatol., 27, 267-276, doi:10.1002/joc.1381.

Richardson, S. J., M. E. Splitt, and B. M. Lesht, 2000: Enhancement of ARM surface meteorological observations during the fall 1996 water vapor intensive observation period. J. Atmos. Oceanic Technol., 17, 312-322.

Simmons, A. J., K. M. Willett, P. D. Jones, P. W. Thorne, and D. P. Dee, 2010: Low-frequency variations in surface atmospheric humidity, temperature, and precipitation: Inferences from reanalyses and monthly gridded observational data sets. J. Geophys. Res., 115, D01110, doi:10.1029/2009JD012442.

Skaar, J., and K. Hegg, 1989: The WMO international hygrometer intercomparison, Norway 1987-89. Papers presented at the Fourth WMO Technical Conference on Instruments and Methods of Observation (TECIMO-IV), WMO/TD-303, IOM Rep. 35, 3-12.

- , — , T. Moe, and K. Smedstud, 1989: WMO international hygrometer intercomparison. WMO/TD-316, IOM Rep. 38, 249 pp.

Sonntag, D., 1994: Advancements in the field of hygrometry. Meteor. Z., 3, 51-66.

Trenberth, K. E., T. R. Karl, and T. W. Spence, 2002: The need for a systems approach to climate observations. Bull. Amer. Meteor. Soc., 83, 1558-1559.

Van der Meulen, J. P., 1988: On the need of appropriate filter techniques to be considered using electrical humidity sensors. WMO/TD-222, IOM Rep. 33, 55 pp.

Vincent, L. A., W. A. van Wijngaarden, and R. Hopkinson, 2007: Surface temperature and humidity trends in Canada for 19532005. J. Climate, 20, 5100-5113.

Visscher, G. J. W., 1995: Standard psychrometers: A matter of (p)references. Meas. Sci. Technol., 6, 1451-1461.

, and J. G. Kornet, 1994: Long-term tests of capacitive humidity sensors. Meas. Sci. Technol., 5, 1294-1302.

Wang, J., H. L. Cole, D. J. Carlson, E. R. Miller, K. Beierle, A. Paukkunen, and T. K. Laine, 2002: Corrections of humidity measurement errors from the Vaisala RS80 radiosondeApplication to TOGA COARE data. J. Atmos. Oceanic Technol., 19, 981-1002.

Wexler, A., and R. E. Ruskin, Eds., 1965: Humidity and Moisture: Principles and Methods of Measuring Humidity in Gases. Vol. 1, Humidity and Moisture: Measurement and Control in Science and Industry, Reinhold Publishing Corp., 687 pp.

Willett, K. M., N. P. Gillett, P. D. Jones, and P. W. Thorne, 2007: Attribution of observed surface humidity changes to human influence. Nature, 449, 710-712.

—, C. N. Williams Jr., R. J. H. Dunn, P. W. Thorne, S. Bell, M. de Podesta, P. D. Jones, and D. E. Parker, 2013: HadISDH: An updateable land surface specific humidity product for climate monitoring. Climate Past, 9, 657-677, doi:10.5194/ cp-9-657-2013.

WMO, 2010: Guide to meteorological instruments and methods of observation. 2008 ed. WMO. [Available online at http://www.wmo.int/pages/prog/www/IMOP/CIMO-Guide. html.]

_ 2011: Manual on codes. Volumes I.1 and I.2, WMO 306. [Available online at http://www.wmo.int/pages/prog/www/ WMOCodes.html.]

Wong, K. C., 2012: A humidity sensor test. Preprints, WMO Technical Conf. on Meteorological and Environmental Instruments and Methods of Observation (TECO-2012), Brussels, Belgium, WMO, P1(29). [Available online at http://www. wmo.int/pages/prog/www/IMOP/publications/IOM-109_TECO2012/Session1/P1_29_Wong_Humidity_Sensor_Test.pdf.]

Wylie, R. G., and T. Lalas, 1992: Measurement of temperature and humidity: Specification, construction, properties and use of the WMO reference psychrometer. WMO Tech. Note 194, WMO-759, 71 pp. 